$10 / 3,24-9785 D$

SANDIA REPORT

SAND97-8224 - UC-406

Unlimited Release

Printed January 1997

\title{
Finite Element Analyses of Tool Stresses in Metal Cutting Processes
}

\author{
Bruce L. Kistler
}

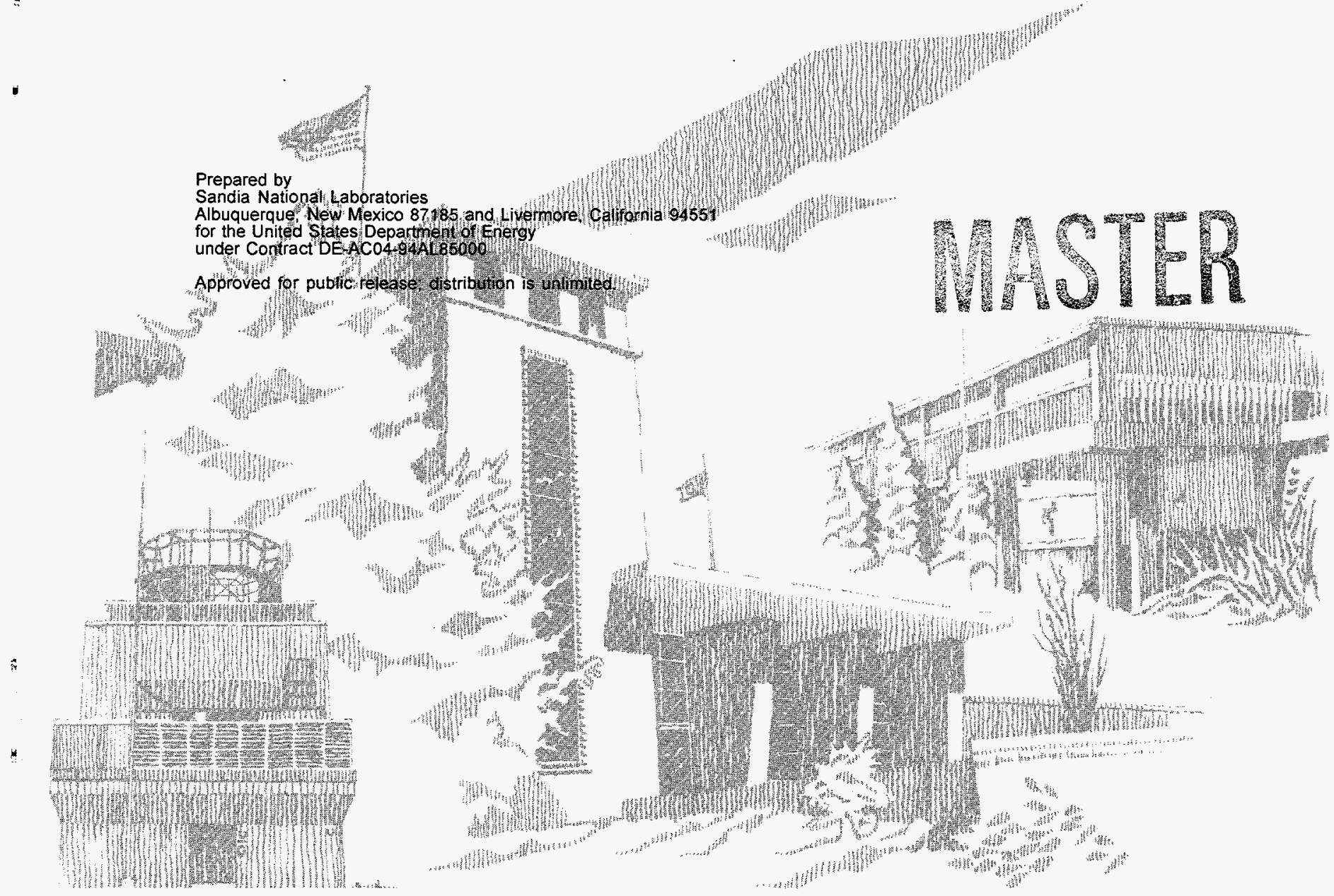


Issued by Sandia National Laboratories, operated for the United States Department of Energy by Sandia Corporation.

NOTICE: This report was prepared as an account of work sponsored by an agency of the United States Government. Neither the United States Government nor any agency thereof, nor any of their employees, nor any of the contractors, subcontractors, or their employees, makes any warranty, express or implied, or assumes any legal liability or responsibility for the accuracy, completeness, or usefulness of any information, apparatus, product, or process disclosed, or represents that its use would not infringe privately owned rights. Reference herein to any specific commercial product, process, or service by trade name, trademark, manufacturer, or otherwise, does not necessarily constitute or imply its endorsement, recommendation, or favoring by the United States Government, any agency thereof or any of their contractors or subcontractors. The views and opinions expressed herein do not necessarily state or reflect those of the United States Government, any agency thereof, or any of their contractors or subcontractors.

This report has been reproduced from the best available copy.

Available to DOE and DOE contractors from:

Office of Scientific and Technical Information

P.O. Box 62

Oak Ridge TN 37831

Prices available from (615) 576-8401, FTS 626-8401.

Available to the public from:

National Technical Information Service

U.S. Department of Commerce

5285 Port Royal Rd.

Springfield, VA 22161 


\section{DISCLAMMER}

Portions of this document may be illegible in electronic image products. Images are produced from the best available original document. 
SAND97-8224

Distribution

Unlimited Release

Printed January 1997

\title{
Finite Element Analyses of Tool Stresses in Metal Cutting Processes
}

\author{
Bruce L. Kistler \\ Structural and Thermomechanical Modeling Department \\ Sandia National Laboratories \\ Livermore, California 94550
}

\begin{abstract}
In this report, we analytically predict and examine stresses in tool tips used in high speed orthogonal machining operations. Specifically, one analysis was compared to an existing experimental measurement of stresses in a sapphire tool tip cutting 1020 steel at slow speeds. In addition, two analyses were done of a carbide tool tip in a machining process at higher cutting speeds, in order to compare to experimental results produced as part of this study. The metal being cut was simulated using a Sandia-developed damageplasticity material model, which allowed the cutting to occur analytically without prespecifying the line of cutting/failure. The latter two analyses incorporated temperature effects on the tool tip. Calculated tool forces and peak stresses matched experimental data to within about $20 \%$. Stress contours generally agreed between analysis and experiment. This work could be extended to investigate/predict failures in the tool tip, which would be of great interest to machining shops in understanding how to optimize cost/retooling time.
\end{abstract}




\section{Acknowledgments}

This study was funded under the Laboratory Directed Research and Development (LDRD) project "Impact \& Thermal Shock Response of Metal Cutting Tools for High Strength, High Speed Milling Operations" case \# 3507240000, which was a two-year project closing at the end of Fiscal Year 1996.

Special thanks go to Anil Reddy, who as a co-op student performed most of the detail of the final Bagchi calculation, and whose excellent internal memorandum write-up was used extensively in this report. Also, special recognition goes to Al McDonald, who initiated and managed this project for the first year. 


\section{Table of Contents}

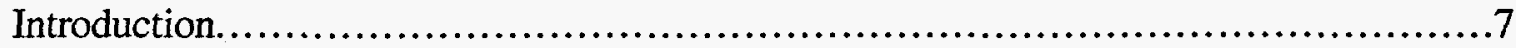

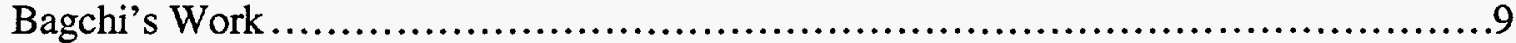

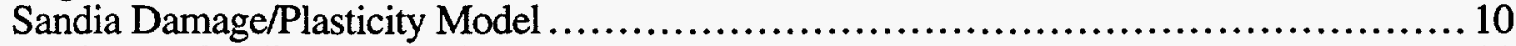

Conjugate Gradient Method ….................................................... 11

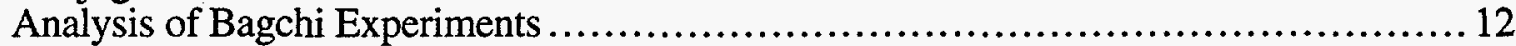

Comparison of Analysis to Bagchi's Experimental Data.............................. 16

Sandia Experiments and Results ....................................................... 19

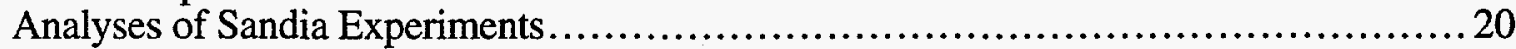

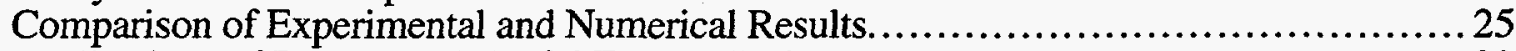

Implications of Results and Useful Future Work ........................................ 32

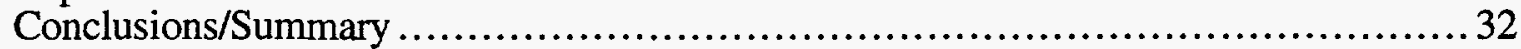

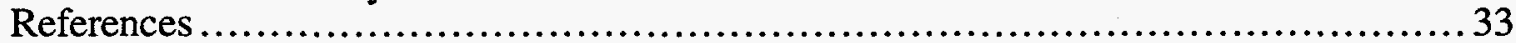

Appendix A: Internal Memorandum of Finite Element Calculations of Bagchi [2] Experiment ............................................. 34

Appendix B: Internal Memorandum of Finite Element Analysis Parameter Study Based on Experiments by Bagchi [2].................................. 38

\section{List of Figures}

Figure 1: In Orthogonal Cutting, Tool Edge is Normal to Direction of Motion ............8

Figure 2: The Setup Used in Bagchi's Experiment [2] ............................. 13

Figure 3: Finite Element Mesh Used for Analysis of Bagchi Experiments................ 14

Figure 4: Finite Element Mesh at Tool Tip for Bagchi Experiments .................... 14

Figure 5: Comparison of Cutting Direction Stress (MPa) for Bagchi Experiment ........ 16

Figure 6: Comparison of Thrust Direction Stress (MPa) for Bagchi Experiment .......... 18

Figure 7: Comparison of Shear Stress (MPa) for Bagchi Experiment................... 18

Figure 8: Finite Element Mesh Used for Modeling Sandia Experiments .................21

Figure 9: Finite Element Mesh at the Tool Tip for Sandia Experiments ..................21

Figure 10: Predicted Tool Temperature Contours

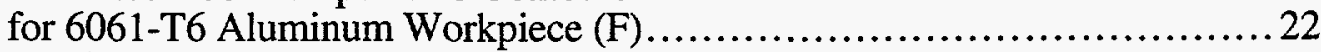

Figure 11: Predicted Tool Temperature Contours

for 304L Stainless Steel Workpiece (F) ….......................... 22

Figure 12: Thrust Direction Tool Strains for 6061-T6 Aluminum Workpiece.............26

Figure 13: Cutting Direction Tool Strains for 6061-T6 Aluminum Workpiece.............27

Figure 14: Tool Shear Strains for 6061-T6 Aluminum Workpiece .....................228

Figure 15: Thrust Direction Tool Strains for 304L Stainless Steel Workpiece .............29

Figure 16: Cutting Direction Tool Strains for 304L Stainless Steel Workpiece ............ 30

Figure 17: Tool Shear Strains for 304L Stainless Steel Workpiece...................... 31

\section{List of Tables}

Table 1: Properties used in the Sandia Damage/Plasticity Model for 1020 Steel .......... 15

Table 2: Material Properties Used in Analysis for Carbide Tool ......................... 23

Table 3: Properties Used in the Sandia Damage/Plasticity Model

for 6061-T6 Aluminum and 304L Stainless Steel ...........................24

Table 4: Measured Microstrain at Specific Locations for Sandia Experiments............ 25 
This page is intentionally blank 


\section{Introduction}

Machining is a common fabrication technique where material is shaved from a part using a tool with a small, hard tip. Usually the material being cut is a metal, such as aluminum or steel, and the standard tool tip is commonly a carbide material. The carbide is often coated with a thin diamond coating to increase the life of the tool tip. In order to quickly fabricate a part, a high cutting speed is desired. These higher speeds, however, lead to a faster degradation of the tool tip, which requires that the tool tip be replaced more frequently. Over the history of machining, guidelines and conventions have arisen based on empirical information of tradeoffs between cutting speed and tool replacement time.

A significant amount of experimental and analytical work has been done on the behavior of the material being cut. The reason is that the final machined product must meet certain design specifications. On the other hand, very little attention has been paid analytically to understanding the behavior of the tool, specifically with regard to extending it's lifetime. This lack of numerical investigation of tool response is surprising, given the possible cost and time savings of extending the life of the tool, which allows either faster cutting speeds or a longer time between retooling.

The purpose of this study was to attempt to both experimentally measure and analytically model the behavior of specific tool tips under controlled cutting conditions. By successfully modeling the behavior and response of the tool tip, we believed that we could then make recommendations for extending tool life based on understanding of the tool failure mechanisms.

To reach that goal, we first examined the existing literature and found only one instance where tool responses, such as stress, had been experimentally measured. With this experimental data, a first finite element calculation was performed to determine the required analytical parameters to effectively predict the tool tip response. The second step was to design and execute some carefully and specifically designed cutting experiments which would provide additional data from other cutting conditions than were available in the literature. Finite element calculations were then performed to compare against this new data. Further refinements of the modeling process could then be made. The final step was to propose likely failure mechanisms and examine perturbations in geometry and/or materials which would make those failures less likely to occur.

In examining failures of tool tips, several different mechanisms appear to be at work. Failure types include getting a built-up-edge, cratering, fracturing of the tip, etc. To some extent, these different types of failure may be associated with different types of cutting environments. For instance, tip fracturing is more likely to occur in an interrupted cutting scenario (such as lathing an object that has an axial groove which the tool would hit at every rotation). In this case, shock waves are generated in the tool both as the tool enters 
and exits the groove, and these shock waves eventually fail the tool tip. Conversely, a longer continuous cut might lead to a built-up edge, which dulls the tool and therefore requires more force for the cutting process. In addition, chips from the cut metal are continuously sticking/sliding over the tool tip, leading to variable local tip stresses which act as a cyclic load. Finally, the process of cutting causes both the material being cut and the local tool tip to heat up, which usually is associated with a decrease in material strength and other properties.

There are also different classifications of machining operations, each of which may have a different force or stress distribution. In orthogonal cutting, the tool edge is normal to the direction of relative motion between the tool and the work material (Figure 1). The lateral spread of the chip is ignored and the deformation process is assumed to be two dimensional. It can be easily achieved by machining the rim of a tube held in a lathe. Orthogonal cutting was the only cutting configuration examined in this study.

In this study, we specifically examined the thermal process, the interrupted cut shock wave scenario, a continuous cut which might lead to a relatively steady state stress condition, and the tool tip stress changes that arise from different geometries associated with failure (such as the built-up edge and cratering). Different parts of this study were undertaken by different personnel, and are written up separately [1]. This report will only discuss the steady state cutting process. Although the original goal of this LDRD (Laboratory Directed Research and Development) project was to be able to understand and predict failure of the tool, this report only covers the finite element calculation of steady state stresses in the tool, and does not address failure mechanisms directly.

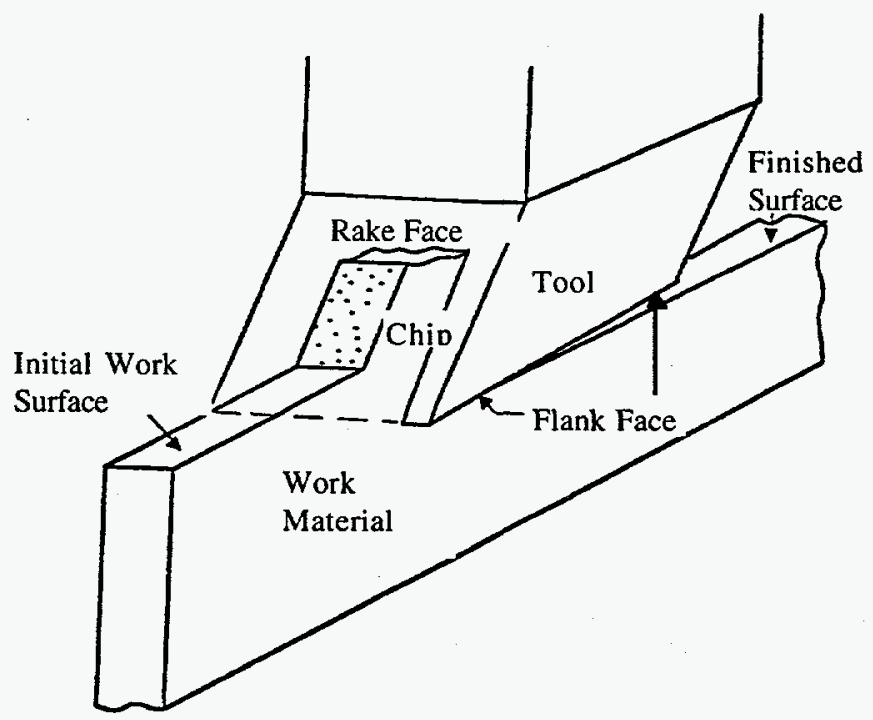

Figure 1: In Orthogonal Cutting, Tool Edge is Normal to Direction of Motion 
The literature search found only one instance where stresses had been experimentally measured in a tool tip. In 1983, Bagchi [2] published a doctoral thesis documenting his work, where he experimentally measured stresses in sapphire tools under slow speed orthogonal cutting conditions. This work became the starting point for our study.

\section{Bagchi's Work}

Bagchi's work [2] was divided into qualitative and quantitative experiments. In the qualitative experiments, he examined the chip-tool interaction both photographically and through post-test observation. In the quantitative experiments, the measurements which Bagchi made were the tool forces, tool stresses (measured as described below), and contact length of the chip. For both sets of experiments, the materials being cut included 360 brass, 1020 steel, and 12L14 steel. Bagchi also used 6061-T6 aluminum in the qualitative experiments. For the qualitative experiments, he used sapphire tool tips (for slow cutting speeds) and carbide tool tips (for commercial cutting speeds), while for the quantitative experiments he used only a sapphire tool tip.

Bagchi used a sapphire tool in his cutting experiments because sapphire is a birefringent material. When load is applied to a birefringent material, ordered sets of lines, called isochromatics and isoclinics, can be observed on the tool surface. The isochromatics and isoclinics are obtained using a plane polariscope. White light produces brightly colored isochromatics and a diffused dark isoclinic. The different isoclinics are obtained for each $15^{\circ}$ interval rotation of the polarizer-analyzer combination. The isochromatics are assigned consecutive integer values while the isoclinics are assigned angles based on the polarizer-analyzer orientation. The isochromatic integers are multiplied by the stress fringe constant (which Bagchi determines via Flamant's line loading technique [3]). The resulting values are the differences in principal stresses along each isochromatic line. The isoclinic angles show the path of the principal stress angle (theta).

Given Bagchi's mapping of the isochromatics and isoclinics, isocline data were found at nodes on a superimposed mesh through interpolation. Bagchi uses the shear difference method to determine the stresses at each of these nodes. The method requires an imposition of suitable boundary conditions and involves marching numerically from an internal row within the tool to the rake face. In order to begin the difference marching, one needs to know the stresses at a particular point. Therefore, he assumed that the shear force and the stress normal to the flank face of the tool were nearly zero at the node farthest from the cutting edge on the flank face. This started the forward difference calculation for 1-direction stresses. Values for the 2-direction stresses were determined using the Mohr's Circle relationship with known shear stress, 1-direction stress, and the difference between principal stresses. Once the stresses are determined in that row of the mesh, stresses in the adjacent row were similarly determined using forward difference. The stresses in the following rows were calculated using a central difference technique. 
Bagchi included a mapping of isoclinics and isochromatics for the 1020 steel experiment but plotted normal and shear stress for the rake face only. In order to more thoroughly compare the analysis to experiment, we determined the stresses at all the nodes on the entire 1-2 plane of the tool. This required going through an interpolation of Bagchi's raw isochromatic and isoclinic data and rewriting his shear difference program to evaluate the stress profile for a 3.39 millimeter square on the 1-2 plane. A 20 by 20 node mesh was used for the shear difference technique.

\section{Sandia Damage/Plasticity Model}

Different techniques have been used in the past to analytically model the metal cutting process. Attempts to model the process of chip formation have for the most part been based on a predetermined line of separation between the workpiece and chip (e.g., Strenkowski and Carroll [4]; Komvopoulos and Erpenbeck [5]). Nodes on this line are separated, and the line "unzipped", when the tool tip is sufficiently close, or when a certain level of plastic strain is attained. Obviously, this approach makes assumptions both on the location and stress level of the "failure" which is the cutting of the metal, and is therefore undesirable in understanding the process. Sekhon and Chenot [6] and Marusich and Ortiz [7], by contrast, have used mesh adaptivity and remeshing to allow for an arbitrary surface of separation. This approach is much more desirable because it more accurately models the cutting process. However, it is a complicated and timeconsuming task to numerically perform the remeshing and mesh adaptivity and is still dependent on the material model to correctly describe the behavior of each element making up the workpiece.

In this study, we employed an intermediate approach. We believe that a complex coupling exists between the tool and workpiece that is a function of the forces, temperature, and history. However, the specific details of chip formation and deformation of the workpiece may not have a direct or significant affect on the toolworkpiece forces or temperature, as long as the overall cutting process is "correct". In general, the location of the cut will be in approximately the location and direction of the tool tip. Thus, we chose to use a finite element mesh which was oriented in that direction. Then, to accurately represent the damage and failure in the workpiece and chip, the Sandia Damage/Plasticity Model [8] was used. This model allows the calculation of accumulated damage in a finite element. Then, we used a capability of the ABAQUS [9] finite element code to turn finite elements "off" when a user-defined parameter level was reached in each element. This eliminated elements which otherwise would have had large distortions (causing convergence problems in the analysis) but which physically had failed or had lost their load carrying capability. Using this approach, we believe that we can adequately represent the cutting/failure/chip formation mechanisms without requiring remeshing or mesh adapting. 
The Sandia Damage/Plasticity material model [8] is a material model which accounts for the deviatoric deformation resulting from the presence of dislocations and dilatational deformation and ensuing failure from the growth of voids. The kinematics of the model are based upon the multiplicative decomposition of the deformation gradient into elastic, deviatoric plastic, and dilatational plastic parts. The constitutive model is formulated with respect to the natural configuration (stress free) defined by the plastic deformation. This results in a structure whose current configuration stress variables are convected with the elastic spin. To model the deviatoric plastic flow, both a scalar and a tensor internal variable are introduced to describe the effects of dislocations in cell walls and cell interiors respectively. The evolution equations for these variables are motivated from dislocation mechanics and are in a hardening minus recovery format. The use of internal state variables and the proposed evolution equations, enables the prediction of strain rate history and temperature history effects. These effects can be quite large and cannot be modeled by equation-of-state models which assume that stress is a unique function of the strain, strain rate, and temperature and independent of the loading path. The temperature dependence of the hardening and recovery parameters results in the prediction of thermal softening during adiabatic temperature rises, and an additional softening is possible due to the anisotropy associated with the evolution of the tensor variable.

The effects of damage due to the growth of voids is included through the introduction of a scalar internal state variable. This variable tends to degrade the elastic moduli of the material as well as to concentrate the stress in the deviatoric flow rule, thereby increasing the plastic flow and leading to another mechanism of softening. When the damage reaches a critical value, failure ensues. The Cocks-Ashby model of the growth of a spherical void in a rate dependent plastic material is used as the internal state variable to describe the evolution of the damage [10]. This equation introduces only one new parameter since it is strongly dependent upon the deviatoric plasticity model.

\section{Conjugate Gradient Method}

In a typical machining operation, thin layers of material are cut off in a repetitive process until the desired total thickness has been cut. In order to accurately capture the behavior of a single layer using finite elements, several elements through the thickness of a single layer are required. Furthermore, finite elements perform best when they are not distorted: that is, where each edge has the same length or at least within a factor of 3 (aspect ratio of 3 to 1). Thus, a large number of small elements were required to model the workpiece behavior accurately, in order to predict the correct load and distribution into the tool tip (which is the structure we were really interested in for this study). For this study, five elements through the chip thickness were used. A large number of time steps were also required in order to watch the cutting process progress and to model chip formation properly. Thus, this problem is not efficiently modeled using an implicit finite element solver, which for each time step has to invert a matrix whose size is related to the number 
of elements. The problem is also not efficiently modeled using an explicit finite element solver, because the time step is limited by the small element size to be several orders of magnitude smaller than the cutting time of interest.

ABAQUS [9] version 5.4 also offered an iterative method for solving sparse systems of linear equations. This method, called the conjugate gradient method, is similar to the explicit method in that it does not require matrix inversions; but its time step is not limited based on the smallest element size. It's drawbacks are that it neglects inertia effects, and that it has the capability of either not converging at all, or of converging to an incorrect answer, if the user is not well-versed in it's use. We chose this method of analysis for this study because we believed that it would provide the most efficient solution for a metal cutting simulation.

\section{Analysis of Bagchi Experiments}

We chose a specific single experiment from Bagchi [2] for our first finite element calculation. Figure 2 shows the setup used in the experiment. The tool was modeled as a rectangle of dimensions $15 \mathrm{~mm}$ rake by $10 \mathrm{~mm}$ flank, with the finest mesh at the cutting tip (Figure 3). The rectangle was rotated five degrees to create a $-5^{\circ}$ rake angle and a $5^{\circ}$ flank angle. The sides opposite the rake and flank faces were restrained from movement in all three directions. The workpiece was also modeled as a rectangle whose base was restrained from movement in the cutting shear and normal directions. The workpiece moved toward the tool tip at an initial rate of $10 \mathrm{~m} / \mathrm{min}$. A layer twice as thick as the uncut chip thickness $(0.132 \mathrm{~mm})$ at the top of the workpiece was given a finer mesh in order to more accurately reflect the chip response after cutting (Figure 4). The bottom and back of the workpiece was assigned a forcing function of $10 \mathrm{~m} / \mathrm{min}$.

Although we recognize that friction is an important factor in the tool-workpiece interaction, we did not include it in our calculations. The interaction between the tool and chip is not well understood, except that it is a source of heat during cutting. We did not want to just assume some type of friction. Furthermore, a portion of this project's goal was to determine whether or not friction affected stresses away from the rake face. By not including friction in the model, comparison of analysis to experimental revealed its effects on tool stress. Frictional heating and convection/conduction were also not accounted for in this calculation.

A contact interface was defined between the surfaces of the tool and any node of the workpiece. This allowed an arbitrary cutting plane to form in the workpiece for which both sides of the cutting plane still had a contact interface with the tool.

We assumed that the tool stresses did not vary greatly with tool thickness (i.e., orthogonal cutting). Therefore, a plane-strain condition was imposed on the three-

dimensional model, which was created with only one element through the depth. The tool 
was made slightly thicker than the workpiece, and the workpiece was centered across the tool "width" for the specific purpose of allowing the contact algorithms in ABAQUS [9] to work more cleanly. The problem was essentially two dimensional, with nodes being restrained in the depth direction. The geometry and mesh were created using MSC/PATRAN [11] before an ABAQUS input file was created. The analysis deck created by MSC/PATRAN for ABAQUS was edited to modify material parameters for use with the Sandia Damage/Plasticity Model [8] and to set the problem up to use a conjugate gradient analysis technique. Post-processing was performed by ABAQUS as well.

Material properties for the sapphire tool tip are: Young's Modulus E $=3.5 \mathrm{E} 11 \mathrm{dyne} / \mathrm{cm}^{2}$ and Poisson's Ratio v $=0.3$. Material parameters for the 1020 steel workpiece for the Sandia Damage/Plasticity model are shown in Table 1.

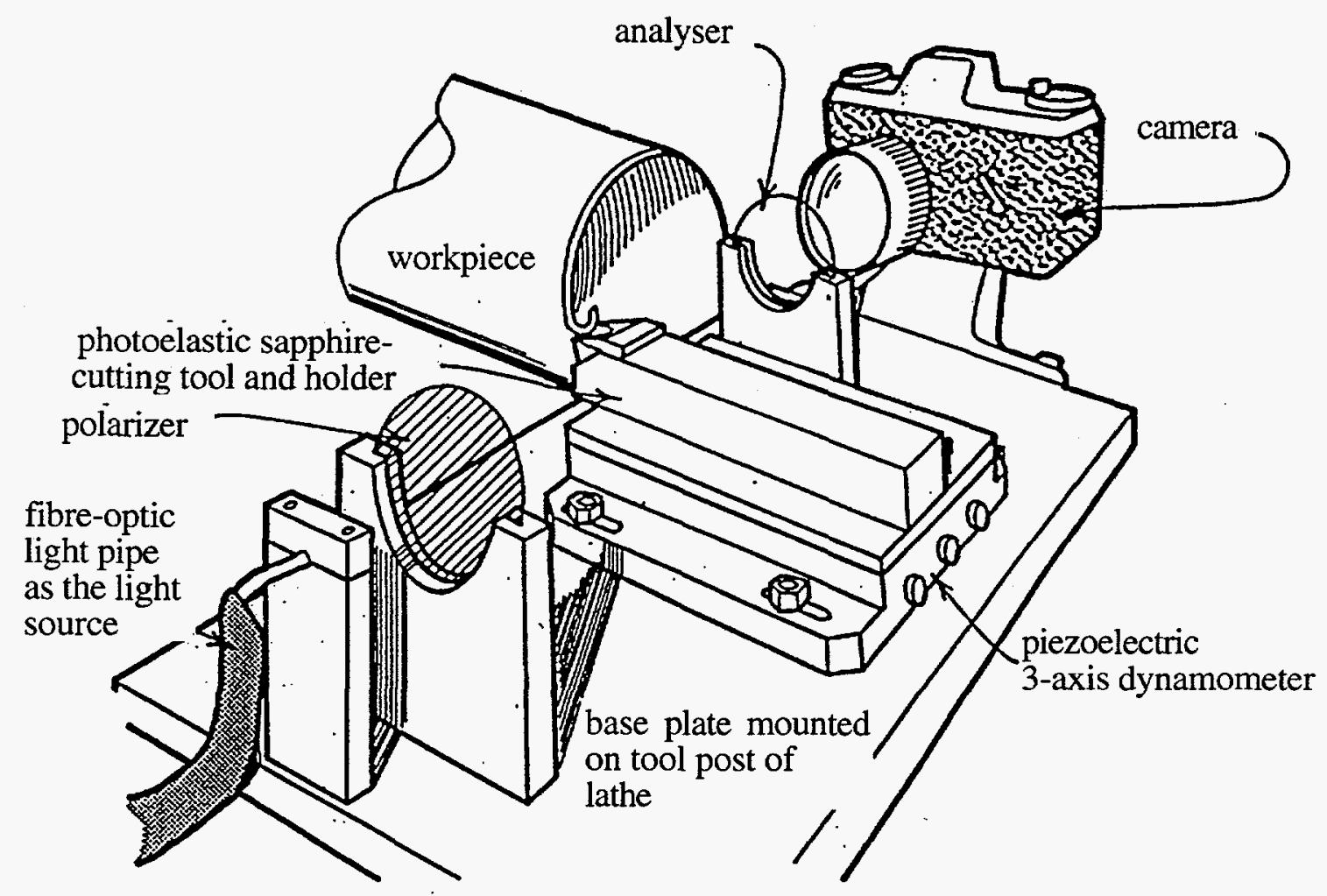

Figure 2: The Setup Used in Bagchi's Experiment [2] 


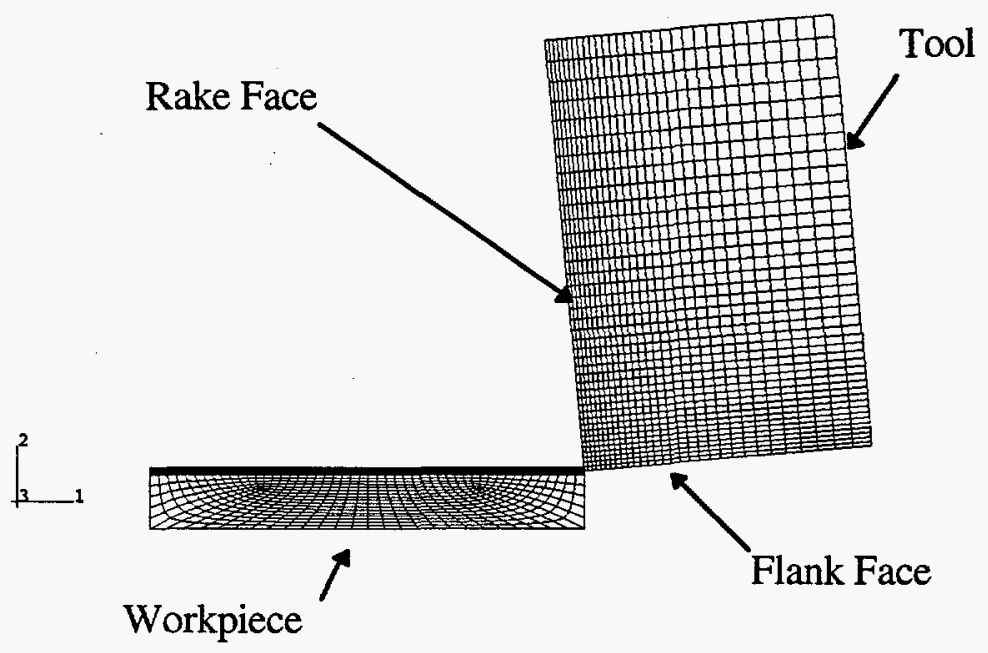

Figure 3: Finite Element Mesh Used for Analysis of Bagchi Experiments

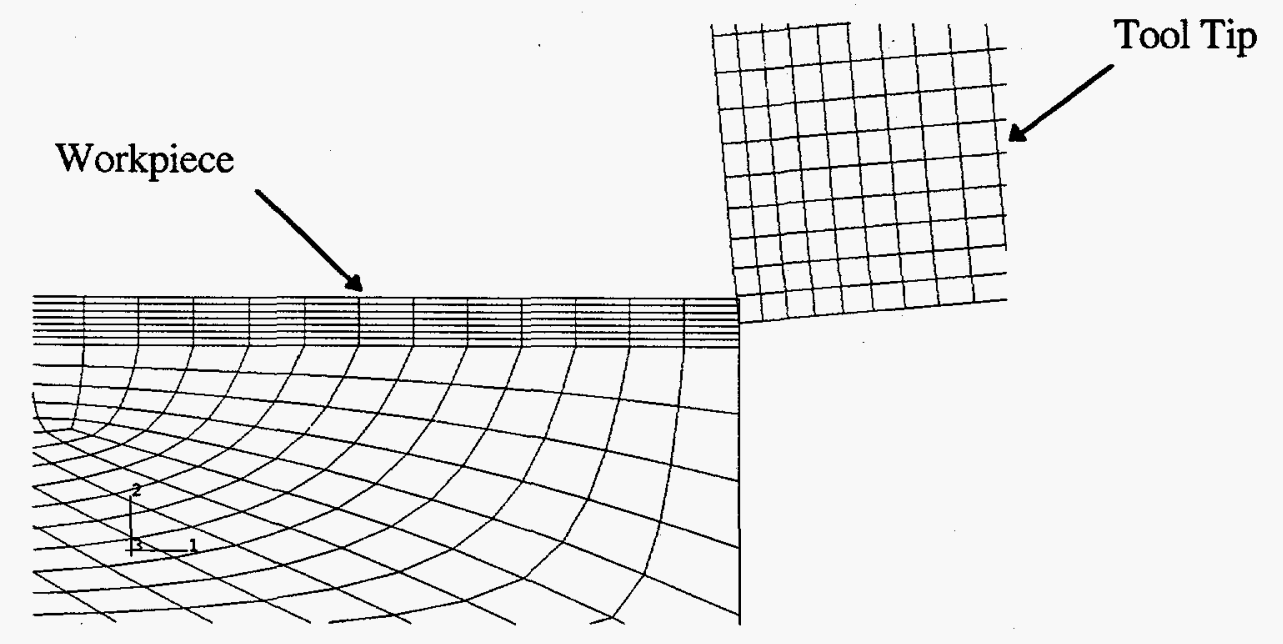

Figure 4: Finite Element Mesh at Tool Tip for Bagchi Experiments 
Table 1: Properties used in the Sandia Damage/Plasticity Model for 1020 Steel

\begin{tabular}{|c|c|c|}
\hline Property/Parameter & Units & Value \\
\hline 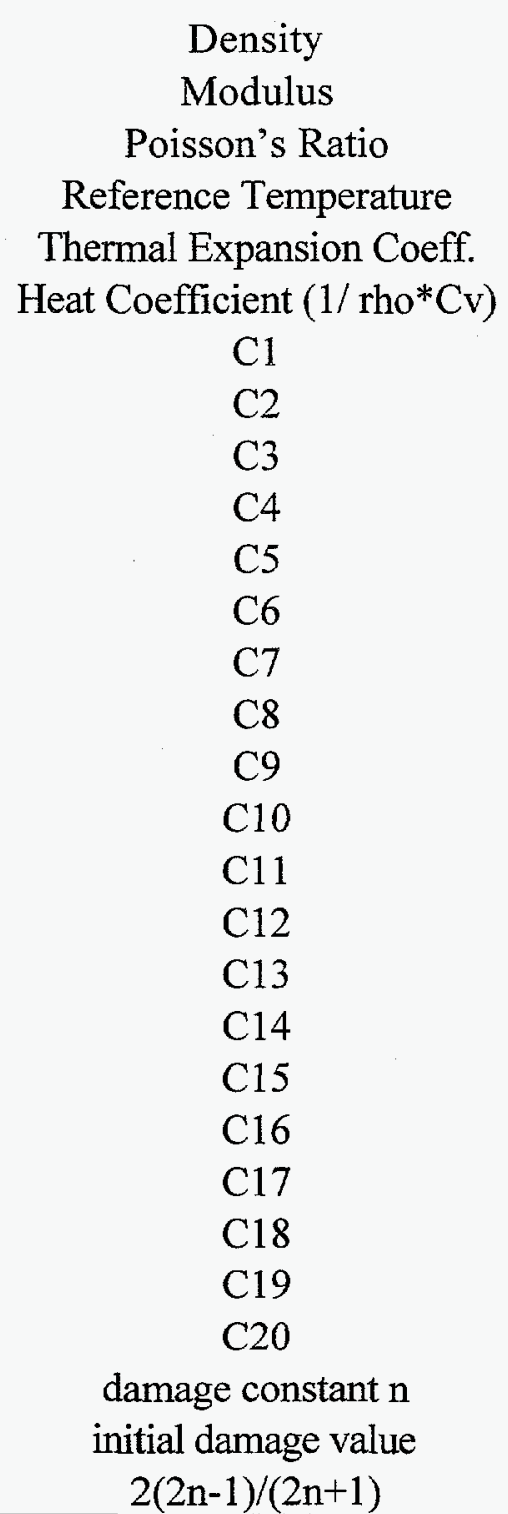 & $\begin{array}{c}\mathrm{Mg} / \mathrm{mm}^{3} \\
\mathrm{MPa} \\
\mathrm{K} \\
1 / \mathrm{K} \\
\mathrm{MPa} \\
\mathrm{K} \\
\mathrm{MPA} \\
\mathrm{K} \\
1 / \mathrm{sec} \\
\mathrm{K} \\
1 / \mathrm{MPa} \\
\mathrm{K} \\
\mathrm{MPA} \\
\mathrm{K} \\
1 /\left(\mathrm{MPa}{ }^{*} \mathrm{sec}\right) \\
\mathrm{K} \\
1 / \mathrm{MPa} \\
\mathrm{K} \\
\mathrm{MPa} \\
\mathrm{K} \\
1 /(\mathrm{MPa} * \mathrm{~s}) \\
\mathrm{K}\end{array}$ & 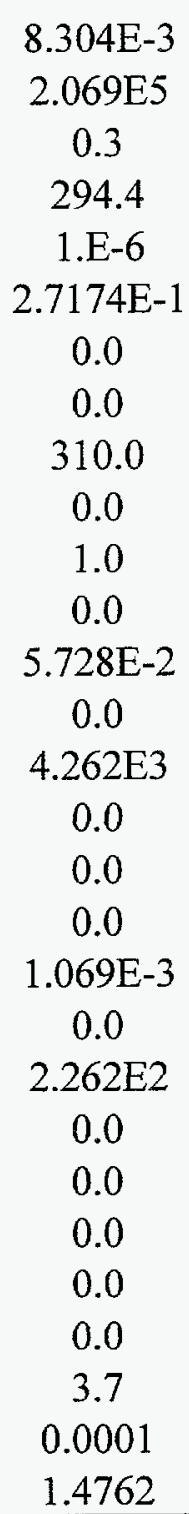 \\
\hline
\end{tabular}




\section{Comparison of Analysis to Bagchi's Experimental Data}

As in the experiment, the high stresses in the tool tip were extremely localized at the cutting tip. The analytical stresses in the cutting direction compared very well with the corresponding experimental stresses (Figure 5). The most notable difference between the two stress profiles is that the spatial gradient of the stress magnitude decreases more quickly with distance in the finite element analysis. In both the analysis and experiment, the stress normal to the rake face dropped to zero at the exact point where the chip left the tool. This was expected, because stresses normal to the rake face are generated by chip contact forces. Since the contact length between the chip and tool is a bit shorter in the calculation ( $0.58 \mathrm{~mm}$ for the analysis and $0.85 \mathrm{~mm}$ for the experiment), the stresses dropped to zero sooner than in the experiment. We believe that in reality, the chip tends to "stick" to the tool as it curls and forms. Therefore, experimental normal (cutting direction) stress is expected to reach a value of zero further up the rake face from the cutting edge than in a frictionless analysis. This hypothesis is supported by these results.

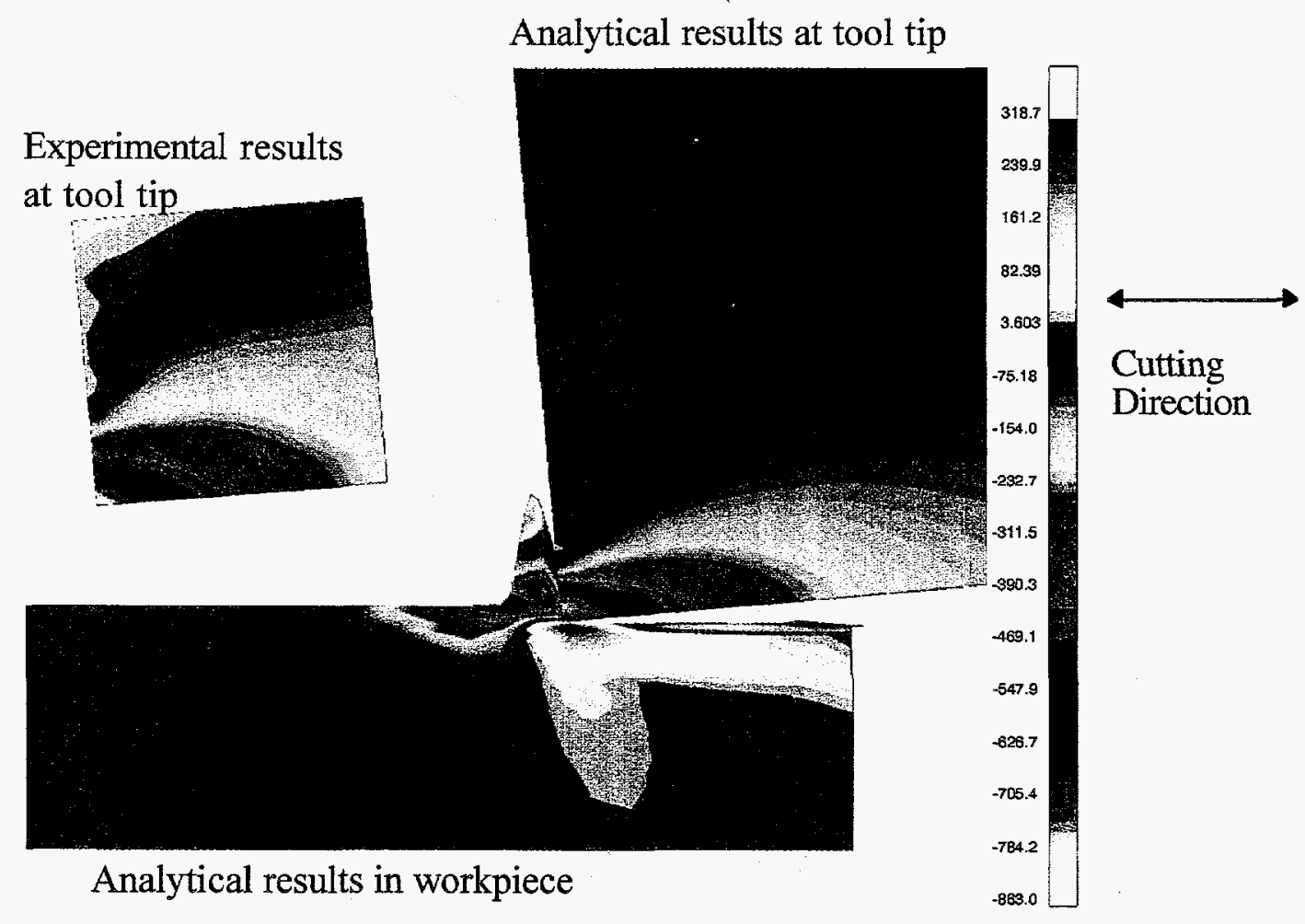

Figure 5: Comparison of Cutting Direction Stress (MPa) for Bagchi Experiment 
In the direction perpendicular to the direction of the cut (thrust direction), there was considerable disagreement between the analytical and experimental stresses at the rake face (Figure 6). We assumed that when the tool cuts the workpiece, the cutting edge of the tool bends down and away from the workpiece. This phenomenon is identical to that of a cantilever beam with a distributed load; the rake face is fixed at one end and the workpiece pushes along the length to displace the tool. As a result of the bending, the rake face should be in tension. This idea is supported by the finite element results shown in Figure 6. The entire rake face is, in fact, in tension, with a single discontinuity in magnitude where the chip leaves the tool. This point of chip departure is especially accented by the angle of the tool. Had the rake angle been zero degrees, the peak in thrust direction stresses along the rake face would have been minimal.

In the experiment, however, friction has a significant effect on thrust direction stresses along the rake face. Without friction, the rake face experiences only tensile bending. But in the experiment, data shows high compressive stress in the region of tool-chip interaction. We claim that in this region, the tool-chip friction acts in a direction opposite of the bending stress, because the chip is sliding up the rake face and "pulling" the cutting edge along with it because of friction. To extend the cantilever beam analogy, the bending forces act along the entire length of the beam, while the chip frictional forces act only along a distance equal to the tool-chip contact length. Because friction induced stress is so much greater than bending stress, the rake face is actually in compression over the contact region. Beyond the contact region, the rake face is once again in tensile bending. The magnitude of tensile stress for the analysis and experiment beyond the contact region are in agreement.

Because there is no force acting beneath the tool in the analysis, thrust direction stresses are zero along the entire length of the clearance (flank) face. However, the effect of flank face bending can be seen in the cutting direction stresses. The analytical and experimental data show large compressive stresses all along the clearance face. In the experiment, there is an additional thrust direction stress that comes as a result of an imperfect, rounded cutting edge. This allows material to flow under the tool, thereby inducing large thrust direction stresses on the flank face.

Although there was considerable disagreement between the thrust direction stresses, their effect on maximum shear stress was minor. Analytical shear stresses agreed very well with experimental shear stresses with respect to shape and magnitude (Figure 7). The conclusion that must be drawn from this result is that cutting direction forces have a much greater effect on internal shear stress than do thrust direction forces. If cutting direction stresses are in agreement, and thrust direction stress are in disagreement, then an agreement in shear stresses suggests that cutting direction forces are the primary motivator of shear stress within the tool. This conclusion is not entirely unexpected, since cutting direction stresses are twice as large as thrust direction stresses in both analysis and experiment. 


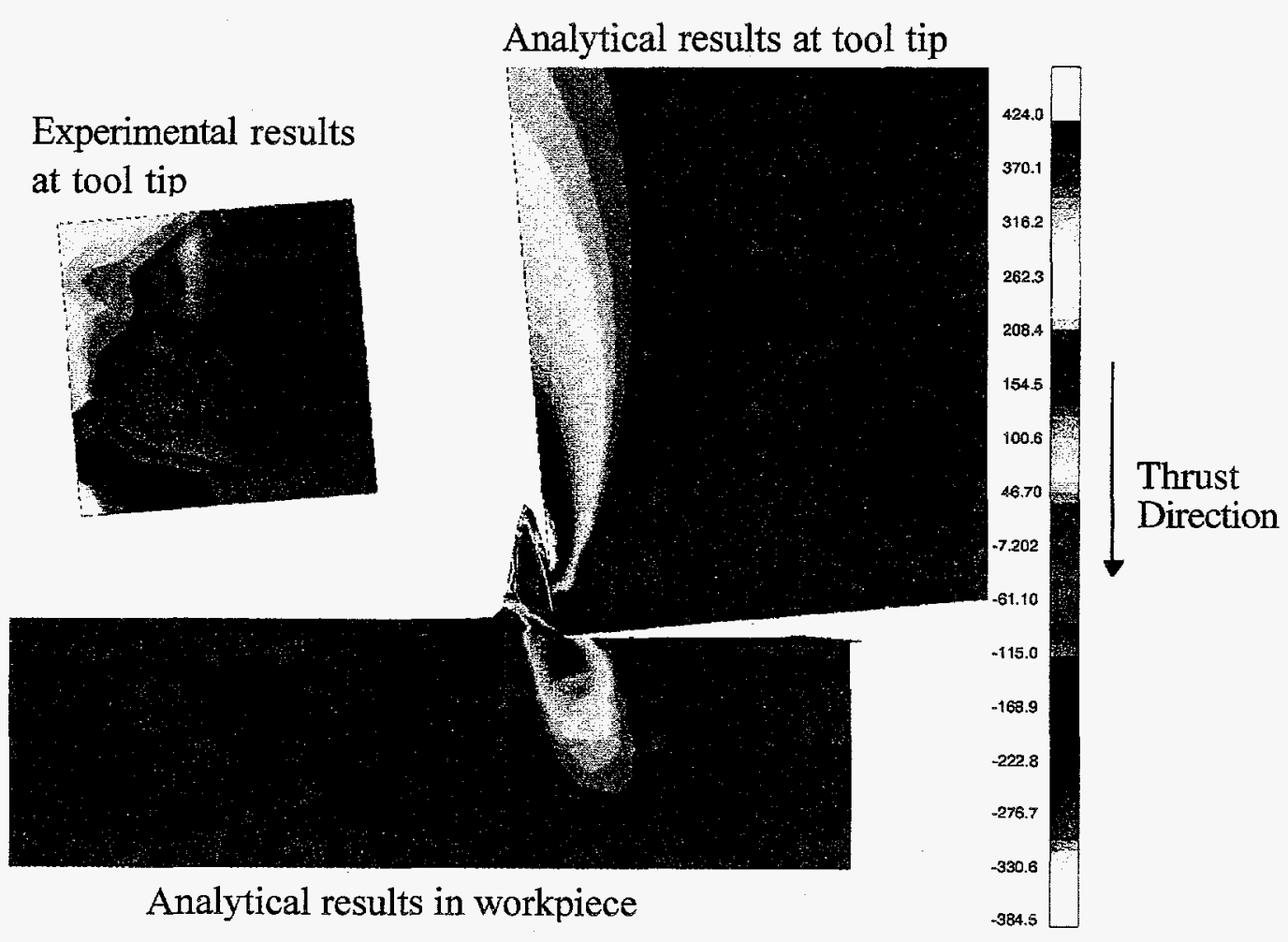

Figure 6: Comparison of Thrust Direction Stress (MPa) for Bagchi Experiment

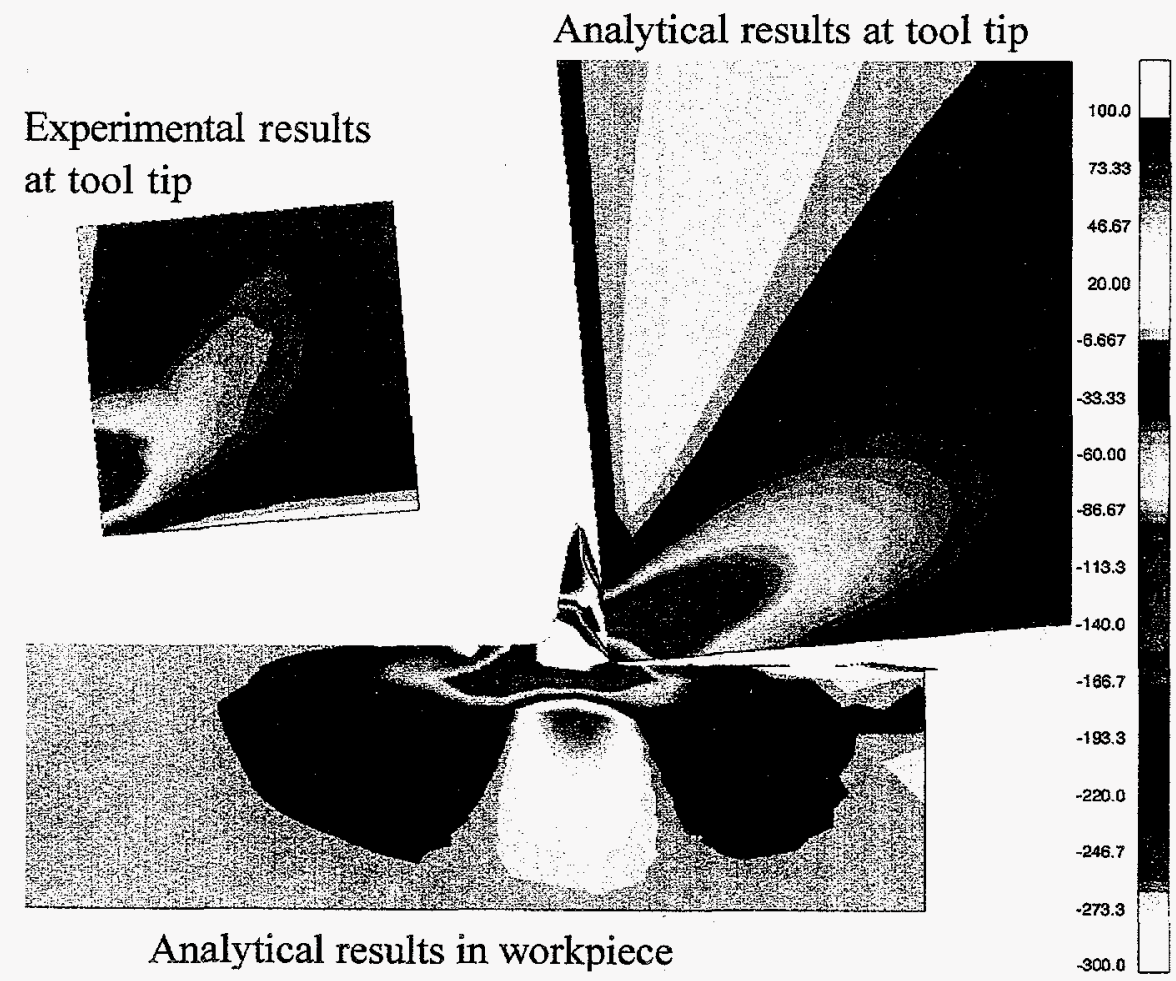

Figure 7: Comparison of Shear Stress (MPa) for Bagchi Experiment 
Another parameter on which friction has a large effect is thrust force. Without friction, the only contribution to thrust force is the small vector component of force which is a result of the chip contacting with the tilted tool. Had the rake angle been zero degrees, analytical thrust force would have averaged zero. Experimental thrust forces, on the other hand, counteracted large frictional forces near the cutting edge. Resulting magnitudes of force were on the order of $1200 \mathrm{~N}$. Average analytical and experimental cutting forces were in agreement to within $25 \%$, with experimental forces being $1800 \mathrm{~N}$ and analytical forces being $2200 \mathrm{~N}$.

Other parameters were looked at numerically as part of this study, including rake angle and cutting speed, even though there were no experimental results to compare against. The internal memorandums of Reddy for the final Bagchi calculation and for these parameter studies is included as Appendices A and B.

\section{Sandia Experiments and Results}

As the next step in the study, an experimental methodology was proposed for measuring localized stresses and temperatures in the tool tip, and a test matrix was proposed and implemented. This test matrix involved carbide-tipped tools with $304 \mathrm{~L}$ stainless steel and 6061-T6 aluminum workpieces. We employed commercial cutting speeds which were faster than for the Bagchi experiments. These measurement techniques and the test matrix and results are described in detail in Reference [1].

Experimental data in the form of strain and temperature were taken at specific point locations in the tool. The technique used was to drill very small diameter access holes from the back of the tool, terminating at the desired gage locations. These locations were chosen based on the results of the analysis of the Bagchi experiment. Unfortunately, the size of the strain gages was too large to capture more than an average of the cutting tip stress, which demonstrated an intense spatial gradient. We also could not consistently locate the gages as close to the cutting tip as needed in order to capture the peak stresses, due to the difficulty of working in the long, small diameter holes. Furthermore, problems in recording the data caused it to be truncated early in time (well before thermal steady state was reached) for most experiments. Thus, the experimental data was composed of thermal data, strain at point locations, and tool forces, but needs to be carefully interpreted.

Two experiments were chosen as candidates for finite element calculations. Both had a rake angle of 0 degrees, a flank angle of 5 degrees, a feed (cutting depth) of 0.0012 inch, and a cutting speed of $452 \mathrm{rpm}$ (88.75 ips). The workpiece was $6061 \mathrm{~T}-6$ aluminum for the first and 304L stainless steel for the second. 


\section{Analyses of Sandia Experiments}

The analysis procedure was similar to that used in modeling the Bagchi experiment. The overall geometry of the tool is shown in Figure 8. Again, the finest mesh was at the cutting tip.

The sides opposite the rake and flank faces were restrained from movement in all three directions. The workpiece was again modeled as a rectangle whose base was restrained from movement in the cutting shear and normal directions. The workpiece was moved towards the tool tip at an initial rate of 88.75 ips. A layer twice as thick as the uncut chip thickness ( 0.0024 in) at the top of the workpiece was given a finer mesh in order to more accurately reflect the chip response after cutting (Figure 9). The bottom and back of the workpiece was assigned a forcing function equal to the initial velocity.

Again, friction was not modeled in these calculations. In this case, there was not enough programmatic time to perform multiple analyses (looking at effects such as friction). However, thermal effects in the tool were taken into account in the structural calculation by mapping a thermal steady state condition onto the tool tip. The thermal maps (Figures 10 and 11) were generated by Chan [1], who used thermal measurements from the experiments in conjunction with a finite element model to provide probable temperature contours in the tool. Although the experiments did not reach thermal steady state in the relatively short cutting time, the rate of increase appeared to be approaching zero. Thus, the contours which Chan generated were mapped as boundary conditions onto the structural model for the purpose of using temperature dependent modulus and strength in the tool tip.

A contact interface was defined between the surfaces of the tool and any node of the workpiece. This allowed an arbitrary cutting plane to form in the workpiece for which both sides of the cutting plane still had a contact interface with the tool.

We again assumed that the tool stresses did not vary greatly with tool thickness (i.e., orthogonal cutting). Therefore, a plane-strain condition was imposed on the threedimensional model, which was created with only one element through the depth. The tool was made slightly thicker than the workpiece, and the workpiece was centered across the tool "width" for the specific purpose of allowing the contact algorithms in ABAQUS [9] to work more cleanly. The problem was essentially two dimensional, with nodes being restrained in the depth direction. The geometry and mesh were created using MSC/PATRAN [11] before an ABAQUS input file was created. The analysis deck created by MSC/PATRAN for ABAQUS was edited to modify workpiece material parameters for use with the Sandia Damage/Plasticity Model [8] and to set the problem up to use a conjugate gradient analysis technique. Post-processing was performed by ABAQUS as well. 


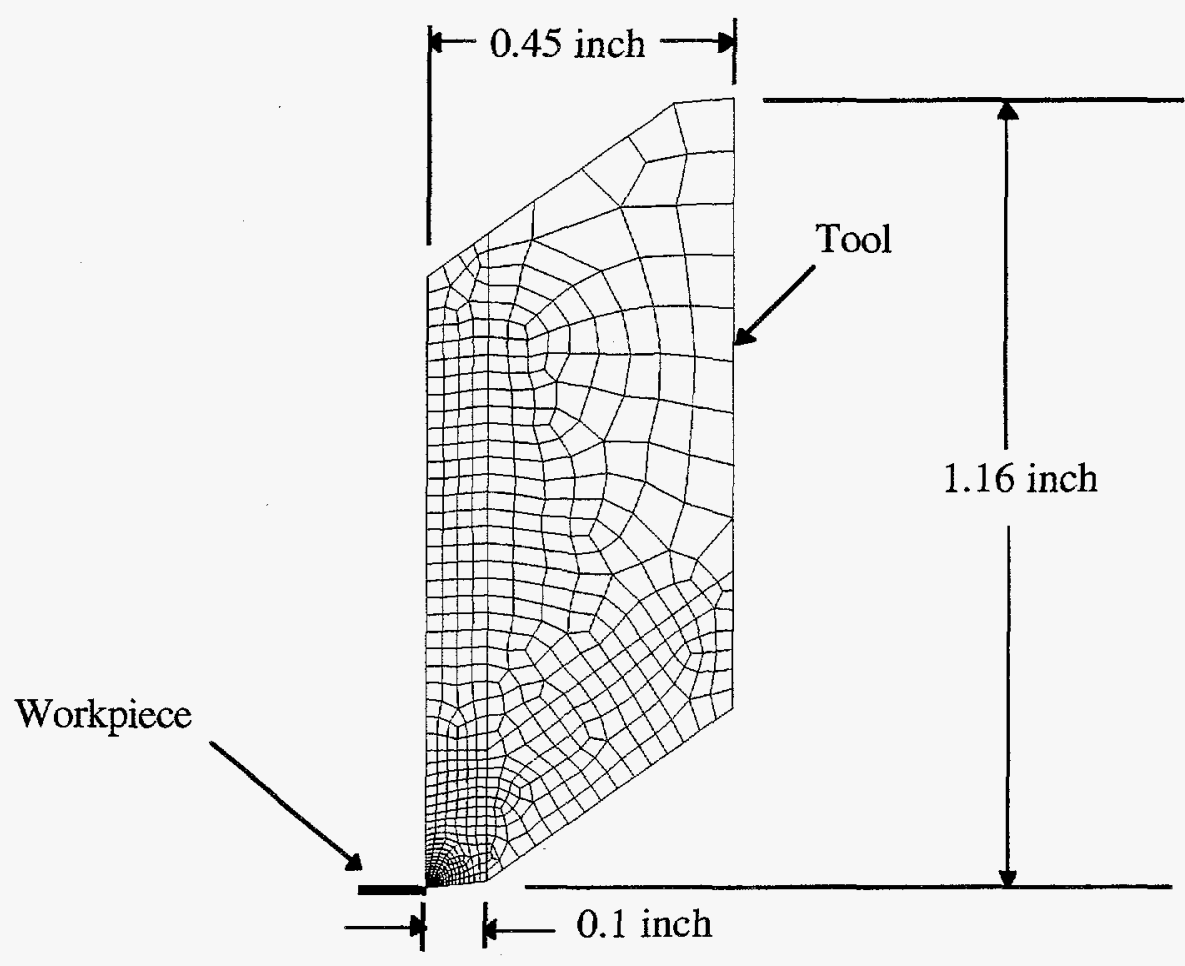

Figure 8: Finite Element Mesh Used for Modeling Sandia Experiments

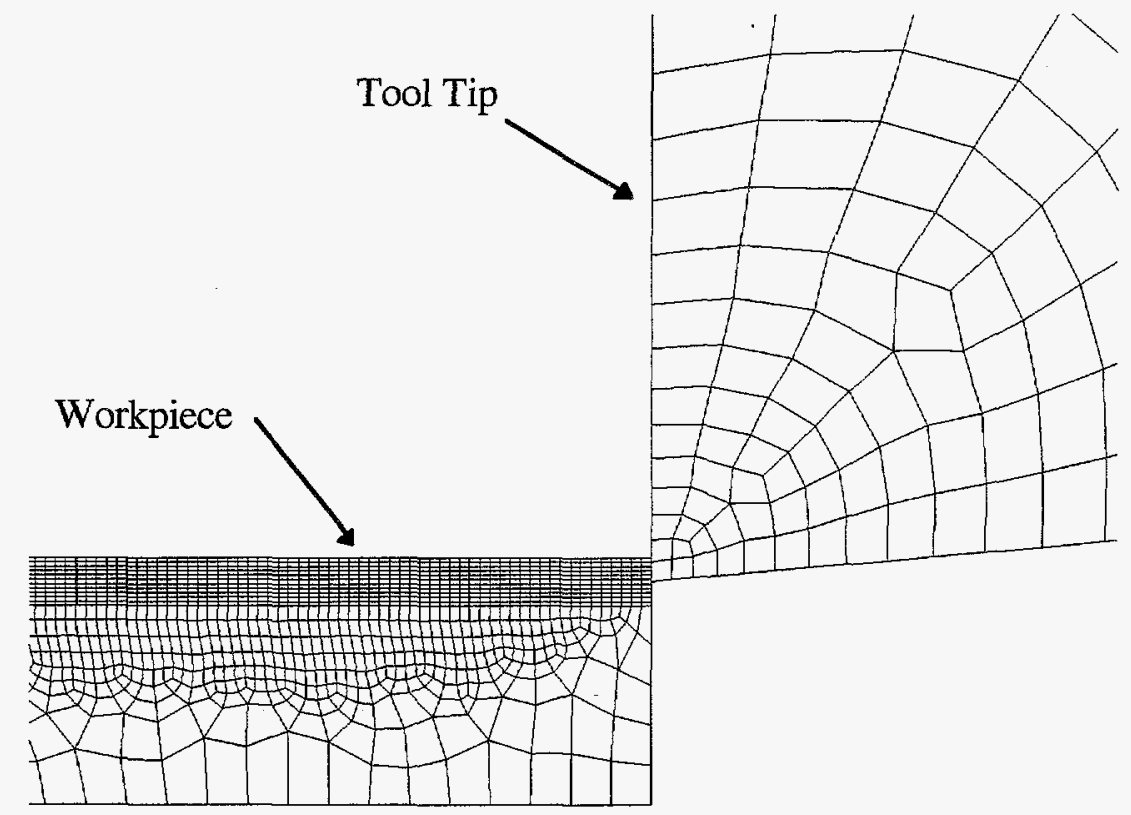

Figure 9: Finite Element Mesh at the Tool Tip for Sandia Experiments 


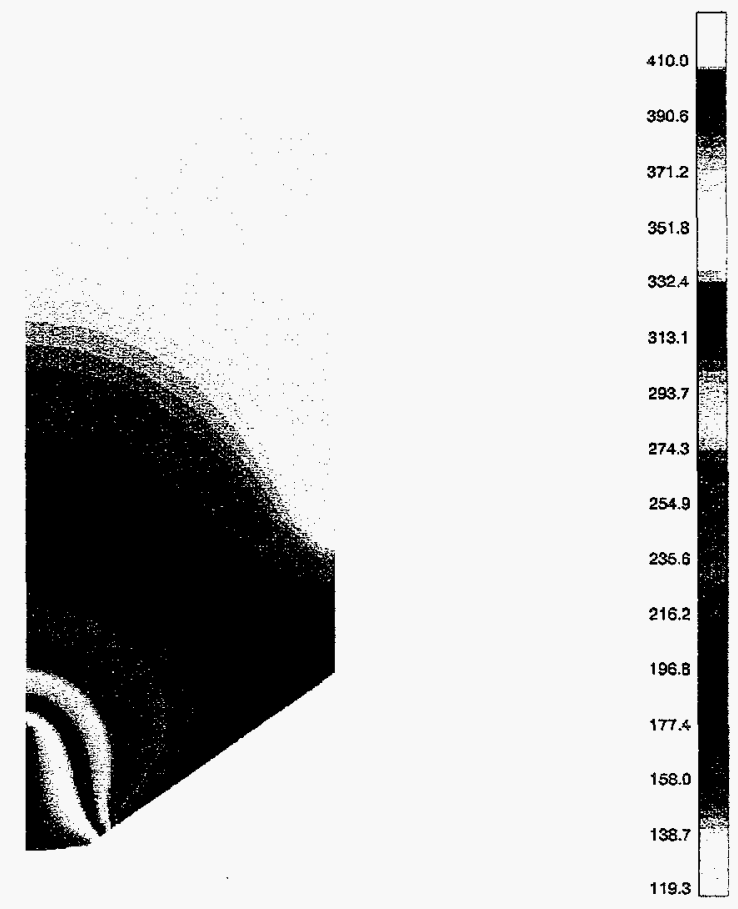

Figure 10: Predicted Tool Temperature Contours for 6061-T6 Aluminum Workpiece (F)
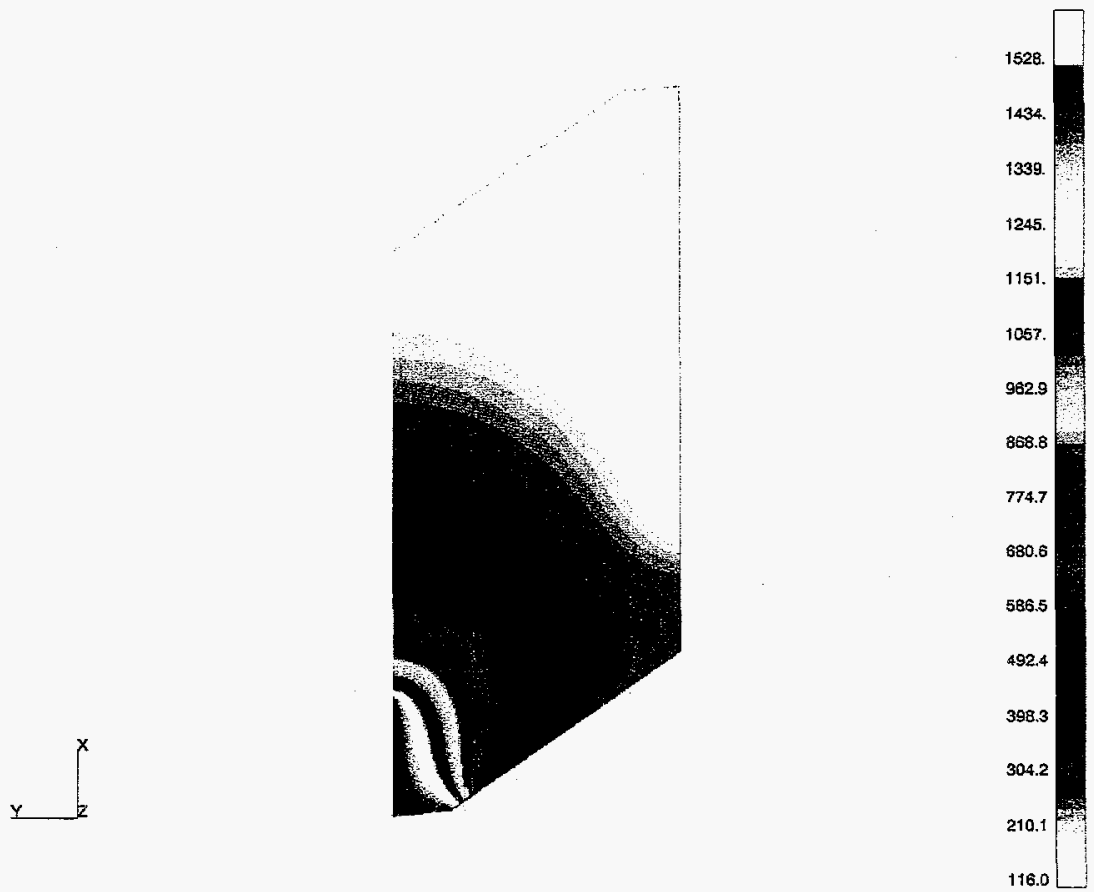

Figure 11: Predicted Tool Temperature Contours for 304L Stainless Steel Workpiece (F) 
Temperature dependent material properties for the carbide tool tip were determined by Mosher [1]. Table 2 summarizes the properties used in this analysis. Material parameters for the 304L stainless steel and 6061-T6 aluminum workpieces for the Sandia Damage/Plasticity model are shown in Table 3.

Table 2: Material Properties Used in Analysis for Carbide Tool

\begin{tabular}{|c|c|c|c|c|}
\hline $\begin{array}{c}\text { Temperature } \\
(\mathrm{R})\end{array}$ & $\begin{array}{c}\text { Modulus } \\
(\mathrm{psi})\end{array}$ & $\begin{array}{c}\text { Poisson's } \\
\text { Ratio }\end{array}$ & $\begin{array}{c}\text { Yield Strength } \\
(\mathrm{psi})\end{array}$ & $\begin{array}{c}\text { TEC } \\
(1 / \mathrm{R})\end{array}$ \\
\hline 559 & $8.3375 \mathrm{E} 7$ & 0.22 & 754000.0 & $2.33 \mathrm{E}-6$ \\
883 & $7.7950 \mathrm{E} 7$ & 0.22 & & \\
1063 & $7.9025 \mathrm{E} 7$ & 0.22 & & $2.56 \mathrm{E}-6$ \\
1243 & $7.4675 \mathrm{E} 7$ & 0.22 & & $2.67 \mathrm{E}-6$ \\
1423 & $7.1775 \mathrm{E} 7$ & 0.22 & & \\
1603 & $6.8150 \mathrm{E} 7$ & 0.22 & & $2.83 \mathrm{E}-6$ \\
1783 & $6.2350 \mathrm{E} 7$ & 0.22 & & $2.89 \mathrm{E}-6$ \\
1963 & $5.5100 \mathrm{E} 7$ & 0.22 & 304500.0 & \\
2143 & $4.9300 \mathrm{E} 7$ & 0.22 & & \\
2323 & $4.0600 \mathrm{E} 7$ & 0.22 & 145000.0 & \\
2503 & & & 58000.0 & \\
$\rho=0.098 \mathrm{lb} / \mathrm{in}^{3}$ &
\end{tabular}


Table 3: Properties Used in the Sandia Damage/Plasticity Model for 6061-T6 Aluminum and 304L Stainless Steel

\begin{tabular}{|c|c|c|c|}
\hline Property/Parameter & Units & 6061-T6 Aluminum & 304L Stainless Steel \\
\hline Density & $\mathrm{lb} / \mathrm{in}^{3}$ & 0.000254 & 0.000732 \\
\hline Modulus & psi & $1.0 \mathrm{E} 7$ & $3.0 \mathrm{E} 7$ \\
\hline Poisson's Ratio & & 0.33 & 0.3 \\
\hline Reference Temperature & $\mathrm{R}$ & 523.0 & 523.0 \\
\hline Thermal Expansion Coeff. & $1 / \mathrm{R}$ & 13.E-6 & $5.0 \mathrm{E}-6$ \\
\hline Heat Coefficient $(1 / \mathrm{rho} * \mathrm{Cv})$ & & 0.0 & 3.1E-3 \\
\hline $\mathrm{Cl}$ & psi & 0.0 & 970.0 \\
\hline $\mathrm{C} 2$ & $\mathrm{R}$ & 0.0 & -1000.0 \\
\hline C3 & psi & $2.32 \mathrm{E} 4$ & 6610.0 \\
\hline $\mathrm{C} 4$ & $\mathrm{R}$ & 291.0 & 842.0 \\
\hline $\mathrm{C} 5$ & $1 / \mathrm{sec}$ & 1.0 & 100.0 \\
\hline C6 & $\mathrm{R}$ & 0.0 & 0.0 \\
\hline $\mathrm{C} 7$ & $1 / \mathrm{psi}$ & $1.32 \mathrm{E}-2$ & $5.72 \mathrm{E}-4$ \\
\hline $\mathrm{C} 8$ & $\mathrm{R}$ & $1.25 \mathrm{E} 3$ & 2.21 \\
\hline C9 & psi & $1.49 \mathrm{E} 5$ & 8.7E4 \\
\hline $\mathrm{C} 10$ & $\mathrm{R}$ & 0.0 & 0.0 \\
\hline $\mathrm{C} 11$ & $1 /\left(\mathrm{psi}^{*} \mathrm{sec}\right)$ & 0.0 & 0.0 \\
\hline $\mathrm{C} 12$ & $\mathrm{R}$ & 0.0 & 0.0 \\
\hline $\mathrm{C} 13$ & $1 / \mathrm{psi}$ & $3.05 \mathrm{E}-4$ & $1.85 \mathrm{E}-4$ \\
\hline $\mathrm{C} 14$ & $\mathrm{R}$ & $1.54 \mathrm{E} 3$ & 701.0 \\
\hline $\mathrm{C} 15$ & psi & $1.21 \mathrm{E} 4$ & $2.185 \mathrm{E} 5$ \\
\hline $\mathrm{C} 16$ & $\mathrm{R}$ & 0.0 & 0.0 \\
\hline $\mathrm{C} 17$ & $1 /\left(\mathrm{psi}^{*} \mathrm{~s}\right)$ & 0.0 & $6.21 \mathrm{E}-6$ \\
\hline $\mathrm{C} 18$ & $\mathrm{R}$ & 0.0 & $6.79 \mathrm{E} 3$ \\
\hline $\mathrm{C} 19$ & & 0.0 & 0.0 \\
\hline $\mathrm{C} 20$ & & 0.0 & 0.0 \\
\hline damage constant $n$ & & 8.0 & 4.0 \\
\hline initial damage value & & 0.0001 & 0.0001 \\
\hline $2(2 n-1) /(2 n+1)$ & & 1.7647 & 1.556 \\
\hline
\end{tabular}




\section{Comparison of Experimental and Numerical Results}

Predicted contours for strains in the cutting direction, the thrust direction, and shear are shown in Figures 12 through 17. Locations of strain gages are marked, and the measured strains (after modifying the measured strain to account for the thermal expansion component) are shown in Table 4. Predicted cutting direction strains and shear strains are consistent with the measured data. The predicted thrust direction strains are different from those observed in the experiment, as in the Bagchi comparisons. Thus, if friction had been included in the calculations, experimental and analytical strains might have been consistent in all directions.

The uncertainty in the strain measurements near the tool tip come from four factors. First, the location of the strain gage was only approximately known, because it was difficult to measure the exact depth of the hole and because it was not possible to guarantee that the strain gage was at the very bottom of the hole. Second, the strain gage size (while small) was so large as to be measuring averaged strain over a location where the analysis predicts that the strain varies greatly. Third, most of the measured strain was thermal strain, rather than mechanical, so the actual quantities of interest were of the same magnitude as the "noise." Fourth, many of the measurements were truncated early in time, and even measurements which lasted for the duration of each experiment indicated that thermal steady state had not yet been achieved. Thus, the "consistency" between the measured and predicted data, mentioned above, means that the measured strain fell within the range of strains predicted for the uncertainty of the measurement.

Measured tool cutting forces were not available from the test data. However, preliminary experiments performed earlier on an aluminum workpiece, with a larger feed (cutting depth) of $0.0029 \mathrm{inch}$, measured cutting direction forces of $180 \mathrm{lb}$. and thrust direction forces of $120 \mathrm{lb}$. We hypothesize that a smaller feed results in a shorter contact length, which might reduce the normal cutting direction force by the same ratio $(0.0012$ inch to $0.0029 \mathrm{inch}$ ). It is also possible that a thinner chip might curl easier, thus reducing the contact length and the resulting forces even further. These hypothesized forces are in the same ballpark as calculated results, in which comparable predicted cutting direction forces were 100-200 lb. for the steel and 30-50 lb. for the aluminum. The analytical thrust direction forces were insignificant because no friction was accounted for in the model.

Table 4: Measured Microstrain at Specific Locations for Sandia Experiments

\begin{tabular}{|c|c|c|c|c|}
\hline & Aluminum & Workpiece & Steel & Workpiece \\
\hline location & $\begin{array}{l}\text { cutting } \\
\text { direction }\end{array}$ & $\begin{array}{l}\text { thrust } \\
\text { direction }\end{array}$ & $\begin{array}{c}\text { cutting } \\
\text { direction }\end{array}$ & $\begin{array}{l}\text { thrust } \\
\text { direction }\end{array}$ \\
\hline at tool tip & 185 & & 517 & \\
\hline $\begin{array}{l}\text { halfway up } \\
\text { rake face }\end{array}$ & & 185 & & 537 \\
\hline
\end{tabular}




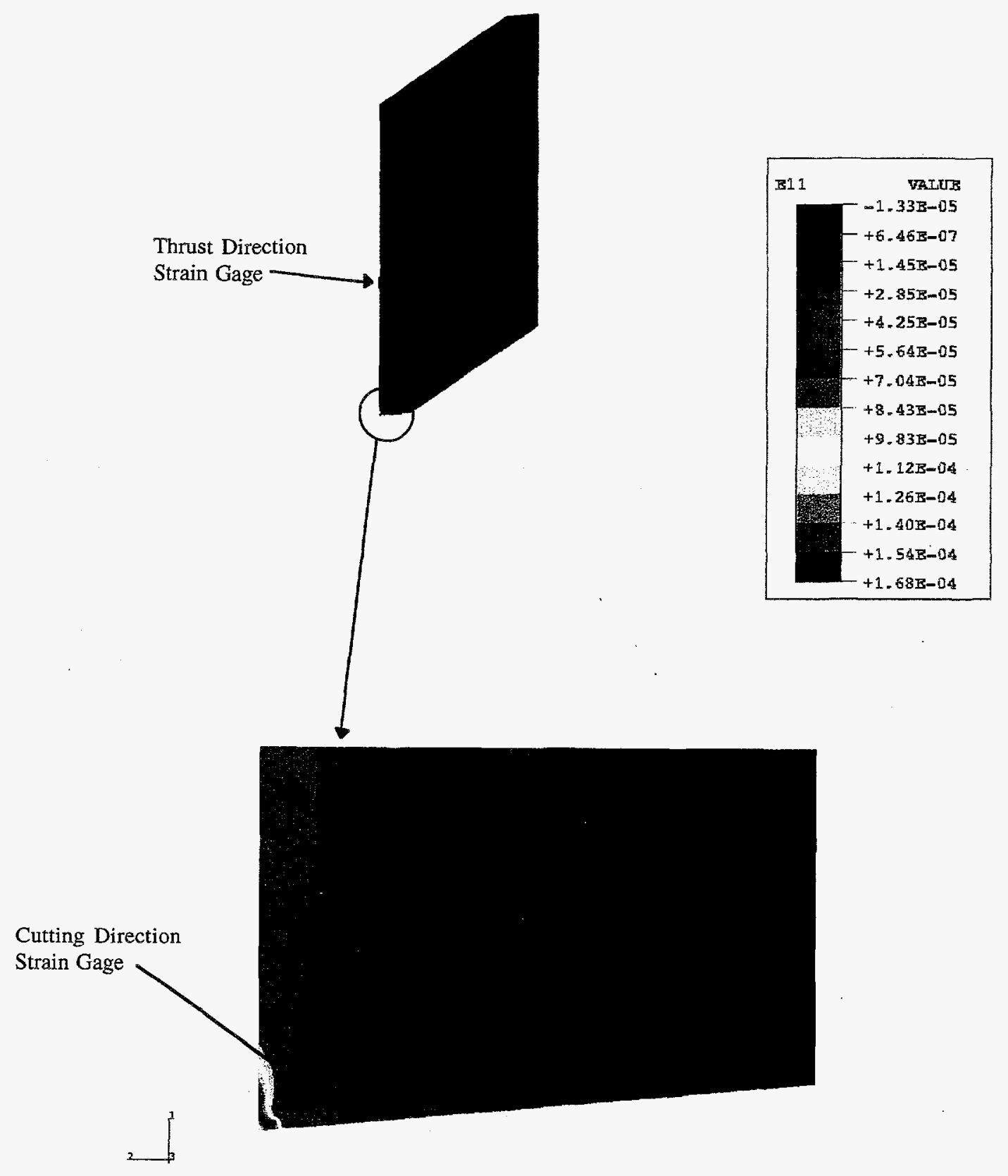

Figure 12: Thrust Direction Tool Strains for 6061-T6 Aluminum Workpiece 


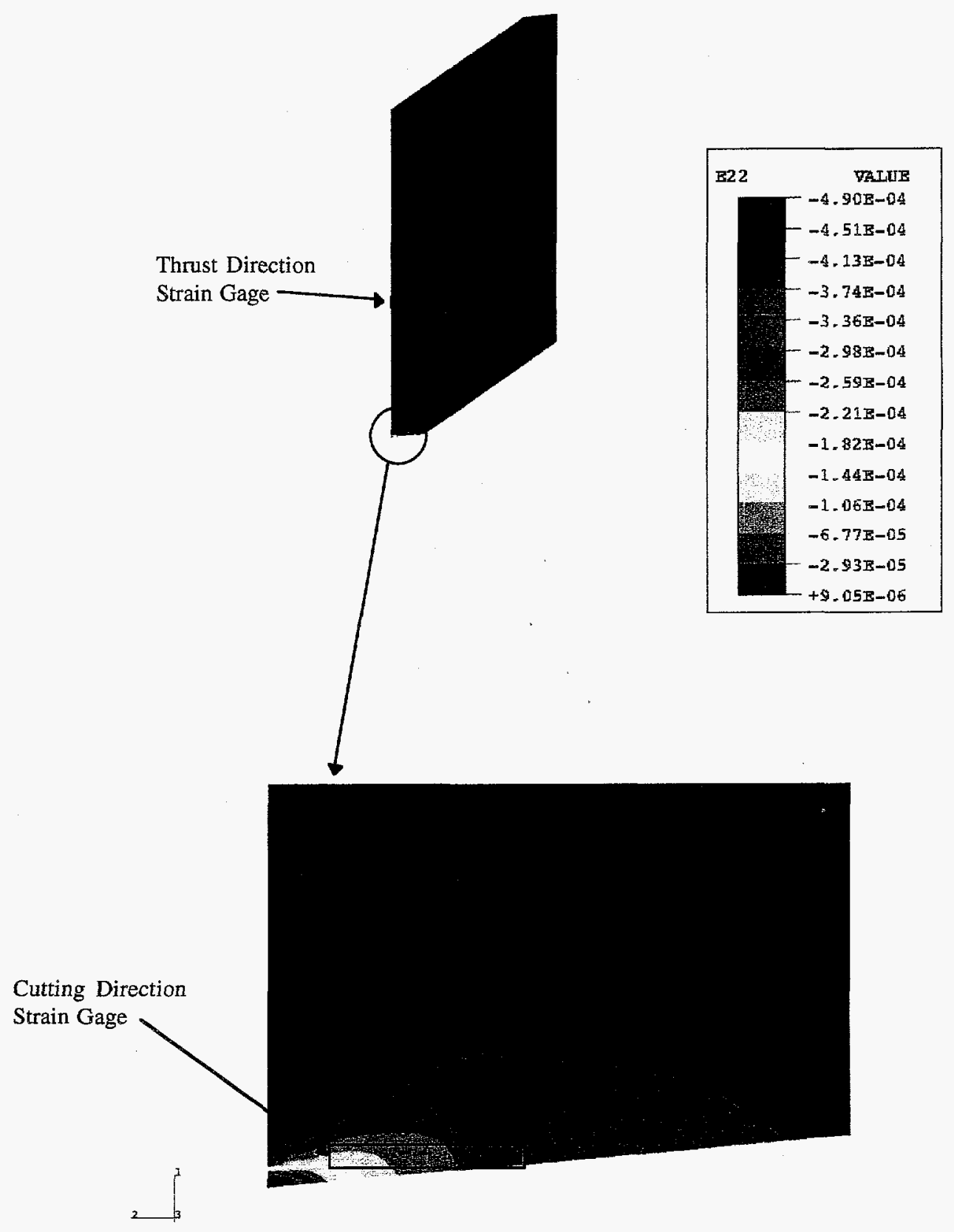

Figure 13: Cutting Direction Tool Strains for 6061-T6 Aluminum Workpiece 


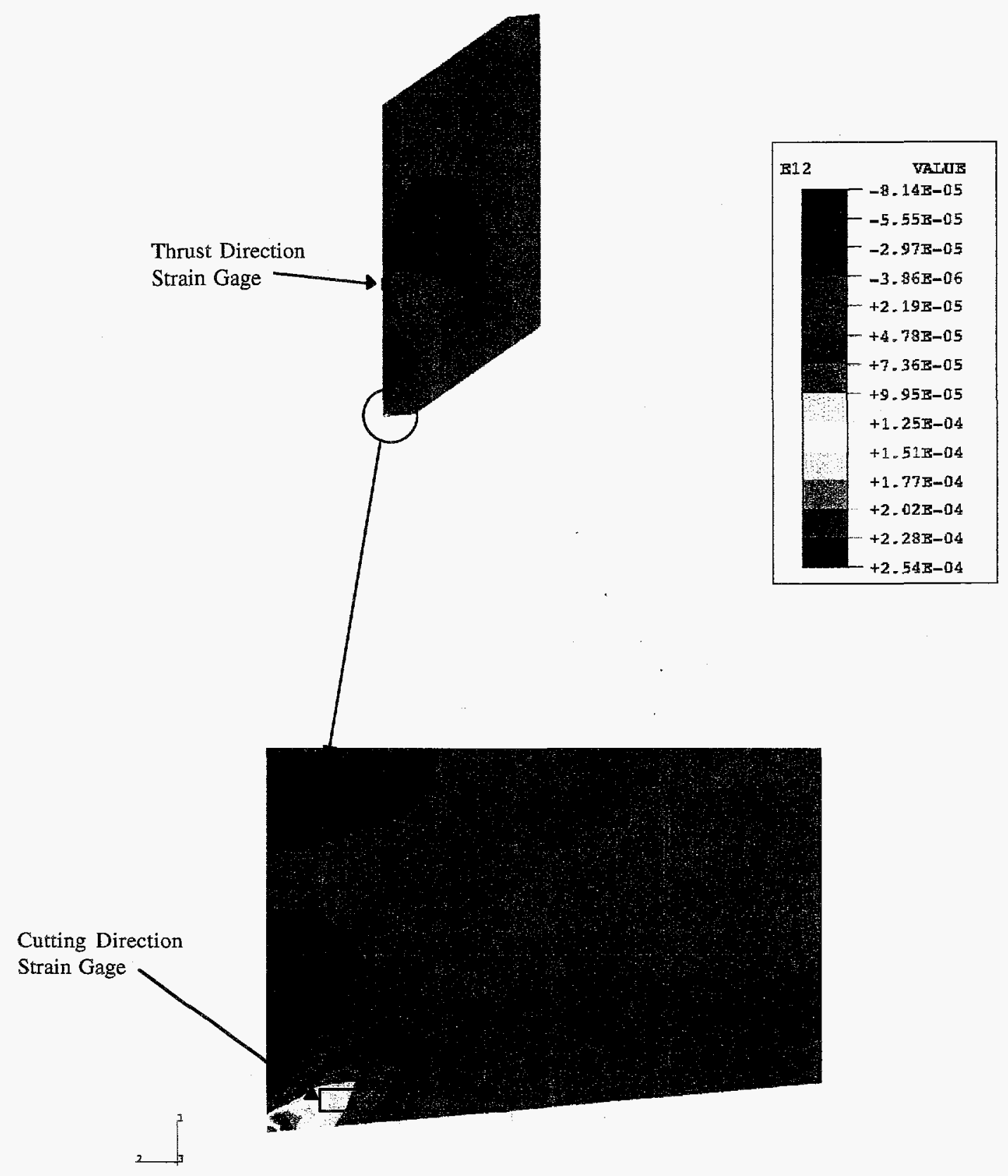

Figure 14: Tool Shear Strains for 6061-T6 Aluminum Workpiece 


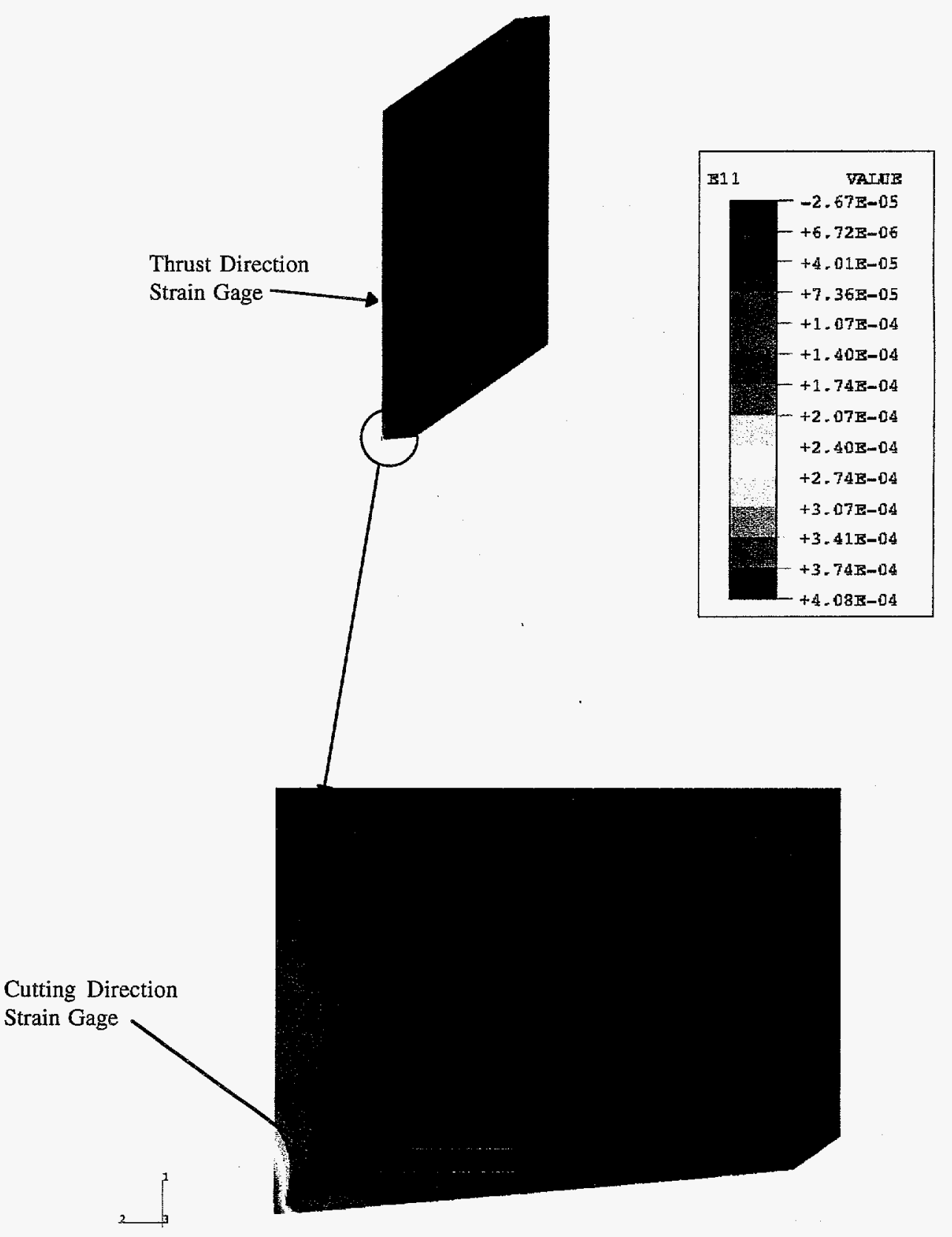

Figure 15: Thrust Direction Tool Strains for 304L Stainless Steel Workpiece 


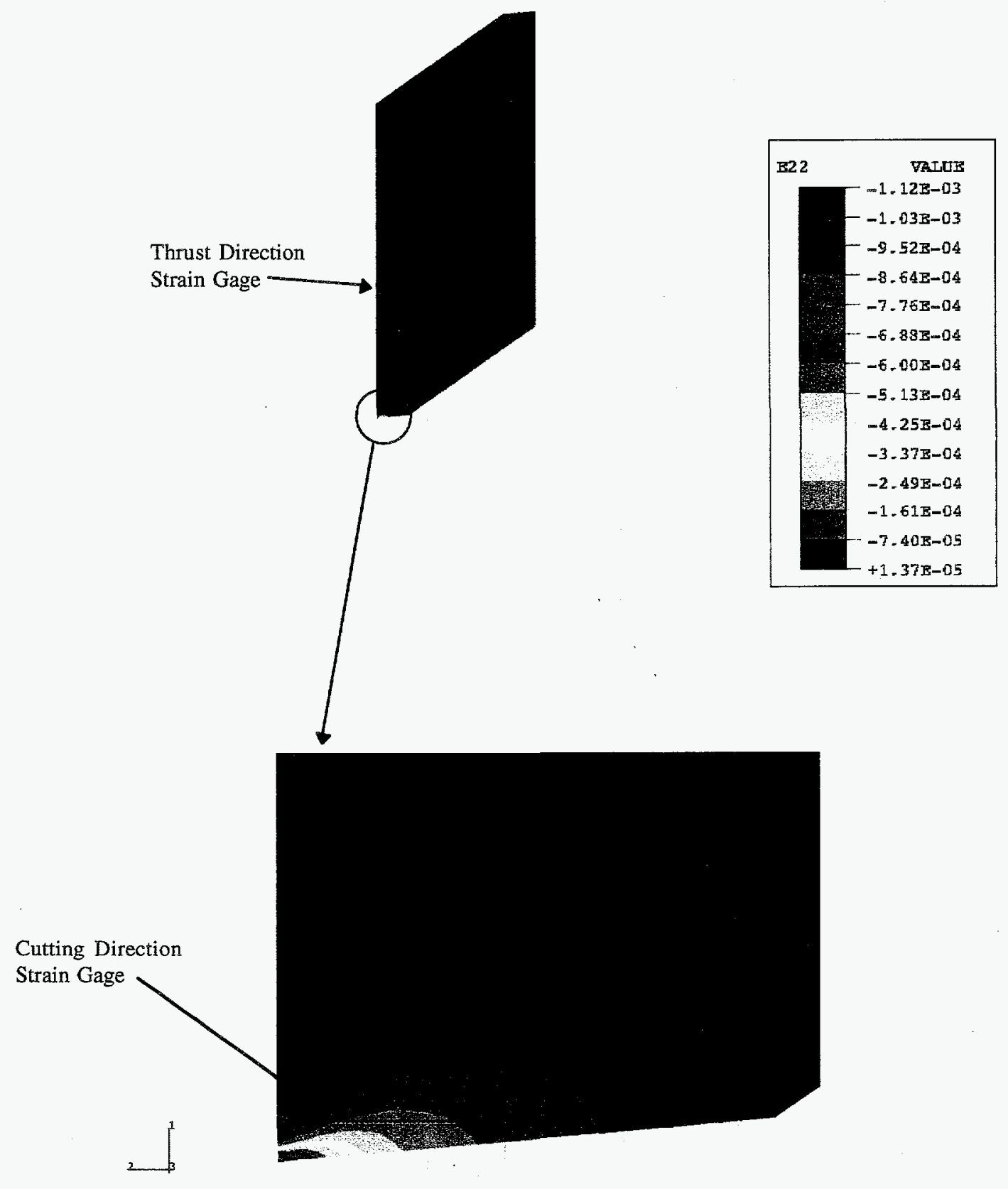

Figure 16: Cutting Direction Tool Strains for 304L Stainless Steel Workpiece 

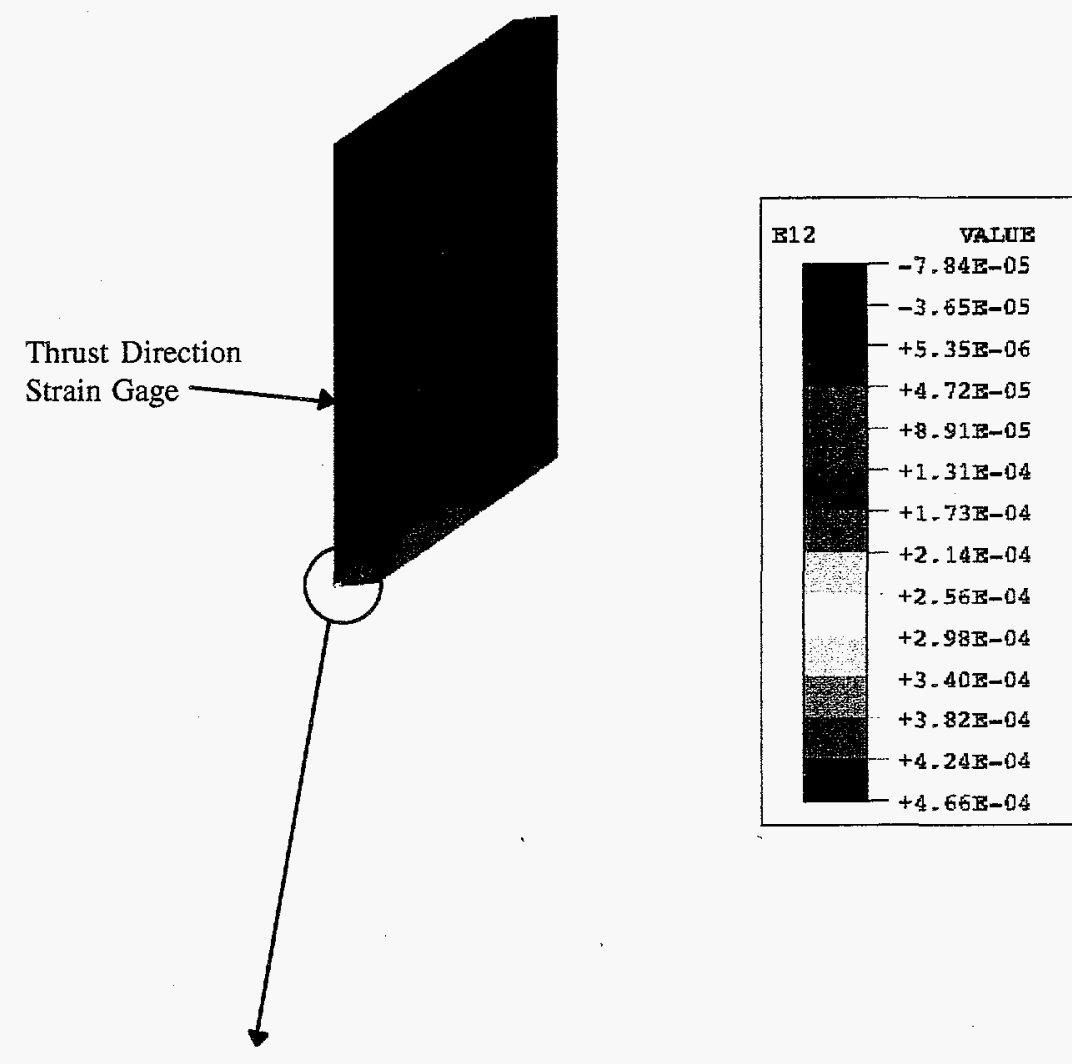

Cutting Direction Strain Gage
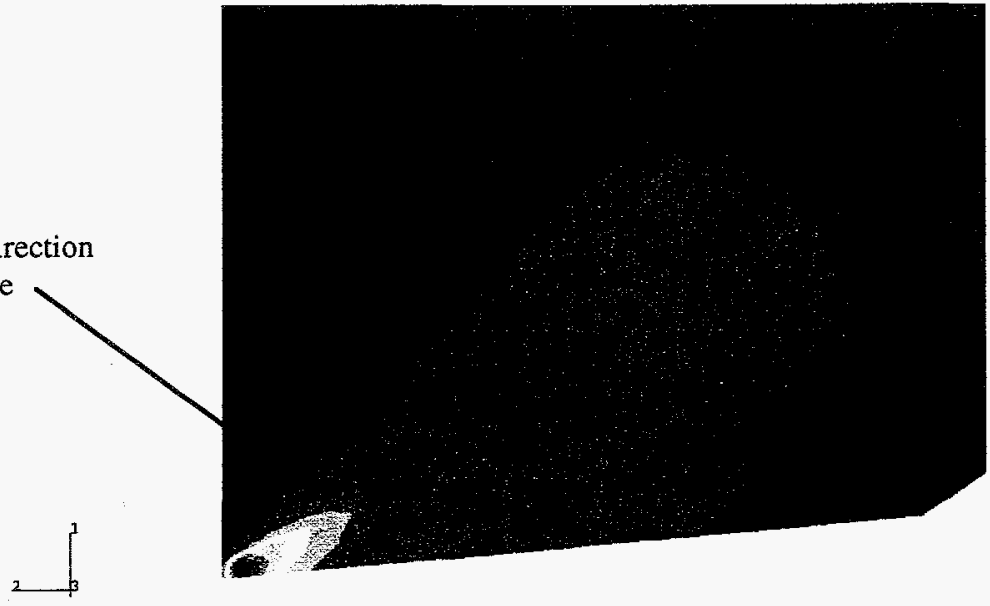

Figure 17: Tool Shear Strains for 304L Stainless Steel Workpiece 


\section{Implications of Results and Useful Future Work}

Numerical results compared favorably with experimental results, such that the methodology of employing finite element analysis to simulate metal cutting processes is encouraged. Inclusion of friction in the calculations would likely have resulted in even better comparisons. Thus, this methodology could be used to examine the stress behavior of tool tips under different cutting environments and with different geometries. For instance, in most cutting operations the tool tip develops a blunt, built-up cutting edge. The effects of that edge could be looked at analytically, at much less expense and in greater detail than with experiment. Also, the effects of different feed rates should be examined to determine the effect on tool stress.

This study does not address interrupted cutting and shock behavior of the tool. A separate type of analysis would need to be done to address that very common scenario. Further, friction models which could take rate dependence into account, and which could be used not only to generate mechanical forces but also friction-induced heating, would need to be incorporated to extend this work further.

\section{Conclusions/Summary}

The finite element method successfully predicted model stresses within sapphire and carbide tools during slow and moderate speed machining. Comparison between numerical and experimental cutting direction and maximum shear stresses were excellent. Discrepancies between predicted and experimental thrust direction stresses were explained to be a function of friction that was not included in the numerical calculation.

Future FEM research should concentrate on understanding the tool-chip interaction zone, especially from a friction and plastic flow standpoint. Additionally, the effects of temperature on tool wear should be investigated. 


\section{References}

1. Hobson, W. T., Kistler, B. L., Chan, J., and Mosher, D., "Modeling and In-Situ Mechanical and Temperature Data for Cemented Carbide Tools Under Realistic Machining Conditions," Sandia National Laboratories, To Be Published.

2. Bagchi, Amit. Photoelastic Stress Analysis in Machining Using Sapphire Tools. Ph.D. Thesis, Carnegie-Mellon University, Pittsburgh. UMI Dissertation Services, Ann Arbor, MI, 1984.

3. Timoschenko, S. P. and Goodier, J. N., Theory of Elasticity, McGraw-Hill Book Company, New York, 1970.

4. Strenkowski, J. S. and Carroll, J. T., III, "A Finite Element Model of Orthogonal Metal Cutting," J. Engrg. Ind., 107 (1985) 349-354.

5. Komvopoulos, K. and Erpenbeck, S. A., "Finite Element Modeling of Orthogonal Metal Cutting," J. Engrg. Ind., 113 (1991) 253-267.

6. Sekhon, G. S. and Chenot, J. L., "Numerical Simulation of Continuous Chip Formation During Non-Steady Orthogonal Cutting," Engineering Computations, 10 (1993) 31-48.

7. Marusich, T. D., and Ortiz, M., "Modelling and Simulation of High-Speed Machining," Int. J. Num. Meth. Eng., TBP.

8. Bammann, D. J., Chiesa, M. L., McDonald, A., Kawahara, W. A., Dike, J. J., and Revelli, V. D., "Prediction of Ductile Failure in Metal Structures," AMD, 107, (1990), 7-12.

9. Hibbitt, Karlsson and Sorensen, ABAQUS/Explicit User's Manual, Version 5.4, 1994.

10. Cocks, C. F. and Ashby, M. G., "Intergranular Fracture During Power-Law Creep Under Multiaxial Stresses," Metal Science, Aug-Sept, (1980), 395-402.

11. MSC/PATRAN, MacNeal-Schwendler Corp., (1996). 


\title{
Appendix A: Internal Memorandum of Finite Element Calculations of Bagchi [2] Experiment
}

\author{
Anil J. Reddy \\ Cornell University, Ithaca, NY \\ Bruce Kistler and $\mathrm{Al}$ McDonald \\ Sandia National Laboratory, Livermore, CA
}

\author{
THE EXPERIMENTAL VERIFICATION \\ OF TOOL STRESSES DURING METAL \\ CUTTING AS PREDICTED BY THE \\ FINITE ELEMENT METHOD \\ -A Preliminary Investigation
}

\section{INTRODUCTION}

The ultimate goal behind the finite element analysis of a machining process is to eventually determine the failure modes of diamond coated carbide cutting tools during interrupted cutting. However, in order to achieve this long range goal, a series of evolutionary steps must be undertaken. The initial step is to experimentally confirm an analytical FEM model for a very simple cutting operation. This in itself is a relatively new arena for researchers; studies of cutting tool stress and their experimental determination are, at best, limited. Much work has been done in the area chip behavior and resulting stresses, but as far as tool stress is concerned, there has been very little finite element research. With the exception of Bagchi's Ph.D. thesis, there is virtually no work available on experimental tool stresses. Fortunately, Bagchi's thesis provides a convenient starting point for the finite element modeling of tool stresses.

The analysis attempts to model the orthogonal cutting of 1020 steel at $10 \mathrm{~m} / \mathrm{min}$ feed rate. This cutting operation is the slowest of the available Bagchi steel experiments. Stress data is available for a $3.39 \mathrm{~mm}$ distance square starting from the cutting corner. A corresponding square of stresses from the model is compared with Bagchi's results.

\section{COMPUTATION OF EXPERIMENTAL STRESSES}

Bagchi used a sapphire tool in all of his cutting experiments because sapphire is a birefringent material. When load is applied to a birefringent material, ordered sets of lines, called isochromatics and isoclinics, can be seen on the surface of the tool. The isochromatics and isoclinics are obtained using a plane polariscope arrangement. The white light produces brightly colored isochromatics and a diffused dark isoclinic. The different isoclinics are obtained for each $15^{\circ}$ interval rotation of the polarizer-analyzer combination. The isochromatics are assigned consecutive integer values while the isoclinics are assigned angles based on the polarizer-analyzer orientation. The isochromatic integers are multiplied by the stress fringe constant (which Bagchi determines via Flamant's line loading technique); the resulting values are the differences in principal stresses along each isochromatics. The isoclinic angles show the path of the principal stress angle, theta.

Given Bagchi's mapping of the isochromatics and isoclinics, isoline data was found at nodes on a superimposed mesh through interpolation. Bagchi uses the shear difference method to determine the stresses at each of these nodes. The method requires an imposition of suitable boundary conditions and involves marching numerically from an internal row within the tool to the rake surface. Bagchi presents the situation as an equilibrium plane stress problem:

$$
\frac{\partial \sigma_{x}}{\partial x}+\frac{\partial \tau_{x y}}{\partial y}=0 \quad \text { and } \quad \frac{\partial \tau_{x y}}{\partial x}+\frac{\partial \sigma_{x}}{\partial y}=0
$$

where sigma and tau are the normal and shear stresses at any point on the mesh. The equilibrium equations can be solved by partial integration and can then be expressed in finite difference form:

$$
\sigma_{x(i+1, j)}=\sigma_{x(i, j)}-\frac{\Delta x\left(\tau_{x y(i, j+1)}-\tau_{x y(i, j)}\right)}{\Delta y} \quad \text { and } \quad \sigma_{y(i, j+1)}=\sigma_{y(i, j)}-\frac{\Delta y\left(\tau_{x y(i+1, j)}-\tau_{x y(i, j)}\right)}{\Delta x}
$$


where the coordinate $(\mathrm{i}, \mathrm{j})$ is a given point on the mesh. The shear stress at each point was determined explicitly from the experimental isochromatics and isoclinics:

$$
\tau_{x y}=\frac{\left(\sigma_{1}-\sigma_{2}\right)}{2} \sin 2 \theta
$$

In order to begin the difference marching, it is necessary to know the stresses at a particular point. Therefore, it was assumed that the shear force and the stress normal to the flank face of the tool were nearly zero at the node farthest from the cutting edge on the flank face. This was the starting point for the forward difference calculation for stresses in the $\mathrm{x}$-direction. Values for the stresses in the $\mathrm{y}$-direction were determined using the Mohr's Circle relationship with known shear stress, $x$-direction stress, and the difference between principal stresses. Once the stresses are determined in that row of the mesh, stresses in the adjacent row were similarly determined using forward difference. The stresses in the following rows were calculated using a central difference technique.

In his thesis, Bagchi included a mapping of isoclinics and isochromatics for the 1020 steel experiment but plotted normal and shear stress for the rake face only. In order to more thoroughly compare the analysis to experiment, it was necessary to find the stresses at all nodes on the entire $x-y$ plane of the tool. This required going through an interpolation of Bagchi's raw isochromatic and isoclinic data and rewriting his shear difference program to evaluate the stress profile for a 3.39 millimeter square on the $x-y$ plane. A 20 by 20 node mesh was used for the shear difference technique.

\section{Finite Element Analysis}

The geometry of the tool for the model was taken from the description in Bagchi's thesis. The tool was modeled as a rectangle of dimensions $15 \mathrm{~mm}$ rake by $10 \mathrm{~mm}$ flank. The rectangle was rotated five degrees to create a $-5^{\circ}$ rake angle and $5^{\circ}$ flank angle. The sides opposite the rake and flank faces were restrained from movement in all three directions. The work was also modeled as a rectangle whose base was restrained from movement in the $y$ and $z$ directions. The work moved towards the tool tip at an initial rate of $10 \mathrm{~m} / \mathrm{min}$. A layer twice as thick as the uncut chip thickness $(.132 \mathrm{~mm})$ at the top of the work was given a finer mesh in order to more accurately reflect the chip response after cutting. The bottom and back of the work was assigned a forcing function of $10 \mathrm{~m} / \mathrm{min}$.

It should be noted here that friction was not modeled in the analysis. The interaction between the tool and chip is not well understood, except that it is a tremendous source of heat during cutting. A portion of this project's goal is to determine whether or not friction affects stresses away from the rake face. By not including friction in the model, comparison of analysis to experimental will reveal its affects on tool stress.

Because stresses do not vary greatly with tool thickness, the geometry models the tool and work as only one element deep. Although the tool was slightly thicker than the work, the problem was essentially two dimensional where all nodes were restrained in the $\mathrm{z}$ direction. The geometry and mesh were drafted using Patran before being sent to Abaqus for analysis. The analysis deck created by Patran for Abaqus was edited to modify material properties and to set the problem up to use a conjugate gradient analysis technique. Conjugate gradient analysis is unlike implicit code in that it does not require the inversion of large matrices, and is thus quicker than an implicit method. However, unlike explicit code, conjugate gradient does not determine its time step size based on element size. Postprocessing was performed by Abaqus as well.

\section{RESUltS AND DisCUSSION}

The analytical stresses in the cutting direction compared very well with the corresponding experimental stresses. The most notable difference between the two stress profiles is how quickly the magnitude of stress decreases in the finite element analysis. In both analysis and experiment, the stress normal to the rake face drops to zero at the exact point where the chip leaves the tool. It is easy to understand why this is expected; stresses normal to the rake face 
are generated by chip contact forces. Because the contact length between the chip and tool is a bit shorter in the analysis, the stresses drop to zero sooner than in the experiment. It is known that in reality, the chip tends to "stick" to the tool as it curls up. Therefore, experimental normal stress is expected to reach a value of zero further from the cutting edge than in a frictionless analysis. This hypothesis is supported by the results.

In the direction perpendicular to the direction of the cut, there was considerable disagreement between the analytical and experimental stresses at the rake face. It is assumed that when the tool cuts the work, the cutting edge of the tool bends down and away from the work. This phenomenon is identical to that of a cantilever beam with a distributed load; the rake face is fixed at one end and the work pushes along the length to displace the tool. As a result of the bending, the rake face should be in tension. This idea is supported by the analytical results. The entire rake face is, in fact, in tension, with a single discontinuity in magnitude where the chip leaves the tool. This point of chip departure is especially accented by the angle of the tool. Had the rake angle been zero degrees, the peak in thrust direction stresses along the rake face would have been minimal.

In the experiment, however, friction has a significant effect on cutting direction stresses along the rake face. Without friction, the rake face experiences only tensile bending. But in the experiment, data shows high compressive stress in the region of tool-chip interaction. It is argued that in this region, the tool-chip friction acts in a direction opposite of the bending stress. This is because the chip is curling up, pulling the cutting edge along with it. To extend upon the cantilever beam analogy, the bending forces act along the entire length of the beam, while the chip frictional forces act only along a distance equal to the tool-chip contact length. Because friction induced stress is so much greater than bending stress, the rake face is actually in compression over the contact region. Beyond the contact region, the rake face is once again in tensile bending. The magnitude of tensile stress for the analysis and experiment beyond the contact region are in agreement.

Because there is no force acting beneath the tool in the analysis, thrust direction stresses are zero along the entire length of the clearance face. However, the effect of flank face bending can be seen in the cutting direction stresses. The analytical and experimental data show large compressive stresses all along the clearance face. In the experiment, there is an additional thrust direction stress that comes as a result of an imperfect, rounded cutting edge. This allows material to flow under the tool, thereby inducing large thrust direction stresses on the flank face.

Although there was considerable disagreement between the thrust direction stresses, their effect on maximum shear stress was minor. Analytical shear stresses agreed very well with experimental shear stresses with respect to shape as well as magnitude. The conclusion that must be drawn from this result is that cutting direction forces have a much greater effect on internal shear stress than do thrust direction forces. If cutting direction stresses are in agreement, and thrust direction stress are in disagreement, then an agreement in shear stresses suggests that cutting direction forces are the primary motivator of shear stress within the tool. This conclusion is not entirely unexpected; cutting direction stresses are twice as large as thrust direction stresses in both analysis and experiment.

Another parameter on which friction has a large effect is thrust force. Without friction, the only contribution to thrust force is the small vector component of force which is a result of the chip contacting with the tilted tool. Had the rake angle been zero degrees, analytical thrust force would have averaged zero. Experimental thrust forces, on the other hand, counteracted large frictional forces near the cutting edge. Resulting magnitudes of force where on the order of $1200 \mathrm{~N}$. Average analytical and experimental cutting forces were agreement to within $25 \%$.

\section{CONCLUSION}

The finite element method was successfully implemented to model stresses within a sapphire tool during machining. Comparison between analytical and experimental cutting direction and maximum shear stresses were good. Reasons for discrepancies between analytical and experimental thrust direction stresses were understood and explained.

Future FEM research should concentrate on understanding the tool-chip interaction zone. Additionally, analysis ought to incorporate temperature and its effects on tool wear should be investigated. Potential short term goals include varying work and tool material as well as altering tool geometry. 
BIBLIOGRAPHY

Bagchi, Amit. Photoelastic Stress Analysis in Machining Using Sapphire Tools. Ph.D. Thesis, Carnegie-Mellon University, Pittsburgh. UMI Dissertation Services, Ann Arbor, MI, 1984. 


\section{Appendix B: Internal Memorandum of Finite Element Analysis Parameter Study Based on Experiments by Bagchi [2]}

Date: August 17, 1995

SANDIA NATIONAL LABS

To: $\quad$ Andy Hazelton (8205), Livermore, California

Bruce Kistler (8742),

Al McDonald (8742)

From: Anil Reddy

\section{Subject: Reaction Forces of Non-Bagchi Cutting Conditions}

In order to further determine the validity of the FEM model, I've run the Abaqus analysis on three slightly altered Bagchi geometries. Three parameters were changed and the resulting average reaction forces were recorded:

\begin{tabular}{|c|c|c|}
\hline \multirow[b]{2}{*}{ CONDITIONS } & \multicolumn{2}{|c|}{ REACTION FORCES } \\
\hline & Cutting Force $(\mathrm{N})$ & Thrust Force (N) \\
\hline Bagchi Experiment & \multirow[b]{2}{*}{-2230} & \multirow[b]{2}{*}{-490} \\
\hline $\begin{array}{l}10 \mathrm{~m} / \mathrm{min} \text { speed } \\
\text { negative } 5 \text { degree rake } \\
.132 \mathrm{~mm} \text { feed }\end{array}$ & & \\
\hline \multicolumn{3}{|l|}{ Increased Speed } \\
\hline $\begin{array}{l}75 \mathrm{~m} / \mathrm{min} \text { speed } \\
\text { negative } 5 \text { degree rake } \\
.132 \mathrm{~mm} \text { feed }\end{array}$ & -2420 & -314 \\
\hline Geometry & \multirow[b]{2}{*}{-1360} & \multirow[b]{2}{*}{110} \\
\hline $\begin{array}{l}10 \mathrm{~m} / \mathrm{min} \text { speed } \\
\text { positive } 5 \text { degree rake } \\
.132 \mathrm{~mm} \text { feed }\end{array}$ & & \\
\hline Increased Feed & \multirow[b]{2}{*}{-3447} & \multirow[b]{2}{*}{-185} \\
\hline $\begin{array}{l}10 \mathrm{~m} / \mathrm{min} \text { speed } \\
\text { negative } 5 \text { degree rake } \\
. \mathbf{2 4 5} \mathbf{~} \mathbf{~ m} \text { feed }\end{array}$ & & \\
\hline
\end{tabular}

Changing tool geometry by increasing rake angle to $+5^{\circ}$ had the expected results. Whereas in the Bagchi geometry, the chip pushed upward on the tool, the chip in a $+5^{\circ}$ rake geometry will push downward on the tool. Therefore, the reaction thrust force has changed sign. Additionally, the magnitude of that reaction is smaller due to the shorter contact length. Cutting force decreased as well - again, as expected since the angle of shear at the chip base is not as sharp in the positive rake geometry.

Increasing feed rate had the effect of increasing cutting force, which is intuitively correct. However, the thrust force magnitude actually decreased. According to experimental data reported by Shaw (in his book, Metal Cutting Principles, page 33), increased feed should increase reaction forces in both the horizontal and vertical directions. 
Shaw's experimental results also show decreasing reaction forces for higher speeds. Although the new speed which I used was on the order of seven times greater than Bagchi's experiment, the resultant forces actually increased, however marginally.

There are three sources of error in the analysis that may have an effect on these comparisons:

1. Comparison of average force through the analysis may not accurately represent the forces through a period of steady state cutting. In the case of the higher speed analysis, it is likely that the forces are very large at impact with the work and then decrease from that point on. I have included plots of force vs. time for the cutting conditions presented above.

2. In the case of unexpected thrust force data, results are largely dependent on the behavior of the chip. Chip behavior, in turn, is governed in part by the material model. It is likely that the material model is not refined enough to represent high strain rates (in the case of faster cutting).

3. Perhaps friction plays a greater, more complicated, role in increasing reaction forces than we had previously realized for non-Baghci cutting conditions. 


\section{UNLIMITED RELEASE}

Initial Distribution

Professor Paul Wright

University of California at Berkeley

Dept. of Mechanical Engineering

Berkeley, CA 94720

Professor Dave Dornfeld

University of California at Berkeley

Dept. of Mechanical Engineering

Berkeley, CA 94720

Sandia Internal:

\begin{tabular}{|c|c|c|c|c|}
\hline MS0188 & 4523 & D. L. Chavez & & \\
\hline MS9007 & 8400 & R. C. Wayne, Attn: & MS9105 8419 & H. H. Hirano \\
\hline MS9042 & 8742 & M. R. Birnbaum & & \\
\hline MS9042 & 8743 & Mike Chiesa & & \\
\hline MS9042 & 8743 & Jay Dike & & \\
\hline MS9042 & 8742 & Jim Handrock & & \\
\hline MS9042 & 8743 & Mark Horstemeyer & & \\
\hline MS9042 & 8742 & Paul Jin & & \\
\hline MS9042 & 8742 & Y. R. Kan & & \\
\hline MS9042 & 8746 & W. E. Kawahara & & \\
\hline MS9042 & 8742 & B. L. Kistler (2) & & \\
\hline MS9042 & 2271 & A. McDonald & & \\
\hline MS9042 & 8742 & Vera Revelli & & \\
\hline MS9042 & 8742 & Jennifer Robles & & \\
\hline MS9042 & 8742 & Arlene Schauer & & \\
\hline MS9042 & 8742 & K. V. Trinh & & \\
\hline MS9042 & 8742 & L. E. Voelker & & \\
\hline MS9042 & 8742 & Larry Weingarten & & \\
\hline MS9105 & 8412 & Jennifer Chan & & \\
\hline MS9105 & 8419 & Bill Hobson & & \\
\hline MS9161 & 8716 & K. L. Wilson & & \\
\hline MS9161 & 8717 & W. G. Wolfer & & \\
\hline MS9402 & 8715 & G. J. Thomas & & \\
\hline MS9403 & 8712 & M. I. Baskes & & \\
\hline MS9403 & 8713 & J. C. F. Wang & & \\
\hline MS9405 & 8743 & Doug Bammann & & \\
\hline MS9405 & 8700 & M. T. Dyer & & \\
\hline MS9405 & 8240 & Calvin King & & \\
\hline MS9405 & 8743 & P. E. Nielan & & \\
\hline MS9420 & 8200 & L. A. West, & $\begin{array}{l}\text { MS94308204 } \\
\text { MS94308240 }\end{array}$ & $\begin{array}{l}\text { L. N. Tallerico } \\
\text { A. J. West }\end{array}$ \\
\hline
\end{tabular}

MS9021 8815 Technical Communications Department, for OSTI (10)

MS9021 8815 Technical Communications Department/Technical Library, MS 0899, 4414

MS0899 4414 Technical Library (4)

MS9018 8940-2 Central Technical Files (3) 